\title{
A systematic approach and software for the analysis of point patterns on river networks
}

\author{
Wolfgang Schwanghart $^{1} \odot$ | Christian Molkenthin ${ }^{2}$ | Dirk Scherler $^{3,4} \odot$
}

${ }^{1}$ Institute of Environmental Science and Geography, University of Potsdam, PotsdamGolm, Germany

${ }^{2}$ Institute of Mathematics, University of Potsdam, Potsdam-Golm, Germany

${ }^{3}$ German Research Centre for Geosciences (GFZ), Earth Surface Geochemistry, Potsdam, Germany

${ }^{4}$ Institute of Geological Sciences, Freie Universität Berlin, Berlin, Germany

\section{Correspondence}

Wolfgang Schwanghart, Institute of Environmental Science and Geography, University of Potsdam, 14476, Potsdam-Golm Germany.

Email: w.schwanghart@geo.uni-potsdam.de

Funding information

Deutsche Forschungsgemeinschaft, Grant/ Award Number: SFB 1294/1 - 318763901

\begin{abstract}
Many geomorphic phenomena such as bank failures, landslide dams, riffle-pool sequences and knickpoints can be modelled as spatial point processes. However, as the locations of these phenomena are constrained to lie on or alongside rivers, their analysis must account for the geometry and topology of river networks. Here, we introduce a new numeric class in TopoToolbox called Point Pattern on Stream networks (PPS), which supports exploratory analysis, statistical modelling, simulation and visualization of point processes. We present three case studies that aim at inferring processes and factors that control the spatial density of geomorphic phenomena along river networks: analysis of a synthetic dataset of points on a stream network, the analysis of knickpoints in river profiles, and modelling spatial locations of beaver dams based on topographic metrics. The case studies rely on exploratory analysis and statistical inference using inhomogeneous Poisson point processes. Thereby, statistical and probabilistic procedures implemented in PPS provide a systematic approach for treating and quantifying uncertainties. PPS offers a consistent numeric framework for modelling point processes on river networks with a wide range of applications in fluvial geomorphology, but also other disciplines such as ecology.
\end{abstract}

KEYWORDS

beaver dams, fluvial geomorphology, knickpoints, point pattern analysis, point processes

\section{1 | INTRODUCTION}

Many geomorphic phenomena along rivers can be represented as spatial point processes. For example, bank failures (Fonstad \& Marcus, 2003; Liang et al., 2015), landslide dams (Korup, 2006; Tacconi Stefanelli et al., 2015; Fan et al., 2020), riffle-pool sequences (Golly et al., 2019), wood jams (Wohl, 2013; Scott et al., 2019), and knickpoints (Berlin \& Anderson, 2007; Phillips \& Lutz, 2008; Gailleton et al., 2019; Schwanghart \& Scherler, 2020) are phenomena that occur at specific locations along rivers and that - at particular spatial scales of analysis - can be represented as point features. Many questions about these processes are inherently linked to their spatial arrangement. For example: Do these phenomena occur randomly in space, or are there mechanisms that cause these phenomena to cluster spatially? Are there interactions between these phenomena that generate some characteristic spacing between them or do additional factors exist that promote their spatial density? A spatial point process is a stochastic mechanism that generates patterns of points in space. The analysis of point patterns - a major subject within the field of spatial statistics - is concerned with understanding and modelling the stochastic and deterministic mechanisms that generate the patterns (Baddeley et al, 2015). While point pattern analysis has pervaded many geoscientific disciplines, there are relatively few applications in geomorphology (Trenhaile, 1971; Oeppen \& Ongley, 1975; Tarboton et al., 1989; Bishop, 2007b, 2007a; Kraft et al., 2011; Clark et al., 2018; Lombardo et al., 2018, 2019; Sochan et al., 2019; Kandakji et al., 2020).

The aim of this study is to explore the opportunities that the analysis of spatial point patterns offers in geomorphology. In particular, we are interested in point patterns that occur along river networks. The network-led spatial configuration makes this kind of analysis challenging. Statistical techniques designed for point patterns in two- 
dimensional (2D) space are usually based on the Euclidean distance between points which can be very different from distances along networks (Okabe et al., 2009; Ang et al., 2012; Rakshit et al., 2017; Moradi et al., 2018; Baddeley et al., 2020). While methodological developments in geostatistics have established a mature set of tools to tackle interpolation along stream networks (Ganio et al., 2005; Cressie et al., 2006; Skoien et al., 2006; Ver Hoef et al., 2006), point pattern analysis on networks is a relatively young and active field of research (Okabe \& Sugihara, 2012; Baddeley et al., 2015).

Here, we present an extension to the MATLAB-based terrain analysis software TopoToolbox (Schwanghart \& Kuhn, 2010; Schwanghart \& Scherler, 2014) called PPS (Point Pattern on Stream networks), which implements the statistical principles and techniques of point pattern analysis on linear networks. PPS complements other tools for point pattern analysis. The R-package spatstat (together with its recent extension spatstat.Knet [Rakshit et al., 2019]) is among the most comprehensive software packages that also handles point patterns on networks (Baddeley et al., 2015) and has strongly influenced the design of PPS. In addition, SANET (Okabe et al., 2006, 2018) is a toolbox for ESRI ArcGIS for analysing events that occur on networks or alongside networks. Incorporating PPS in TopoToolbox offers seamless workflows including data import, analysis, modelling and visualization in the MATLAB programming environment. The ease of working in one computational programming environment and the availability of computational tools for working with river network data was a major motivation to develop PPS alongside TopoToolbox.

In the following text, we provide a brief introduction to spatial point processes, their application in geomorphological research and their modelling on linear networks. We then outline how PPS is implemented in TopoToolbox and demonstrate a number of tools. Subsequently, we present an analysis of synthetic point patterns and two applications in which point pattern analysis serves as an approach to investigating and modelling the occurrence of geomorphic forms and processes along river networks.

\section{2 | SPATIAL POINT PROCESSES}

Point pattern analysis is a branch in spatial statistics that studies the spatial arrangement of points. A point pattern consists of a set of locations of events or features that are the realization of a stochastic process in a bounded study region. In other words, these locations are the outcome of a mechanism which point pattern analysis seeks to explore, describe and explain (Gatrell et al., 1996). Such analysis, however, will only rarely, if ever, fully characterize this mechanism. Rather, it aims to reveal some of its properties. It has proven useful to classify these properties into first- and second-order effects or variations (Gatrell et al., 1996). First-order variations arise from spatial trends or other covariates that control the spatial density of points. For example, the spatial density of bank collapses along a river is a function of the type of rocks or sediments, but may additionally be controlled by spatial trends in water level fluctuations, river gradient and planform geometry (Fonstad \& Marcus, 2003; Liang et al., 2015). Bank collapses can also impact the occurrence of other events of bank failures. Once a bank has failed, river flow patterns may change and thus make adjacent banks susceptible to failure due to debuttressing. Close to an existing bank failure we might thus expect even more bank failures. In this case, we hypothesize a second-order effect due to direct physical interactions that cause bank collapses to be more frequent close to other failures. Another example for a second-order variation is the effect of seed dispersal on the spatial density of plants, but we may also think of processes that inhibit small distances between adjacent points such as the competition for nutrients, light and water.

Point pattern analysis commonly aims to identify first- and second-order effects as departures from complete spatial randomness (CSR). CSR means that the expected number of events is independent from any spatial trend or covariate, and that event locations are spatially independent from each other. The probability of having a point in a certain location is not affected by the absence or presence of other points. The point process that generates such an arrangement is the homogeneous Poisson point process. However, comparing spatial point patterns against this null-model rarely is an end in itself. Rather, it provides the starting point from where point processes of firstand/or second-order variations can be explored (Gatrell et al., 1996). The inhomogeneous Poisson point process, for example, considers nonstationary processes and the effects of spatial trends and covariates on point densities while assuming absence of point interactions. Log-Gaussian Cox processes extend this assumption to unobserved variables represented by a realization of an underlying stationary process with spatial autocorrelation (Diggle et al., 2013). Dependence between points is often called interaction, which encompasses numerous ways how events can influence other events, causing them to be apart or to agglomerate (Baddeley et al., 2015). The class of Neyman-Scott models conceptualizes point clusters as randomly dispersed realizations around a (unobserved) set of parent points. Gibbs models, in turn, explicitly incorporate interactions in their formulation and are flexible models for both attracting and repelling points (Baddeley et al., 2015). Hawkes processes (Hawkes, 1971) are self-exciting processes, that is the occurrence of an event can trigger a sequence of future events. This class of point processes has been widely used to model spatio-temporal seismicity patterns (mainshocks and aftershocks) (Ogata, 1998; Molkenthin et al., 2020).

Point pattern analysis aspires to infer point process models from one (or sometimes several) realization of points. Evidence for any of the models can be evaluated based on the statistical significance of model terms, and where applicable incorporating prior knowledge in a Bayesian framework (Korup, 2020). Although inferring mechanisms from point patterns by this approach might appear straightforward at first glance, model fitting in point pattern analysis is often challenging (Brandolini \& Carrer, 2020).

\section{3 | POINT PATTERN ANALYSIS IN GEOMORPHOLOGY}

A central theme in geomorphology is the spatial assemblage of landforms. Once the spatial scale of analysis permits to conceptualize these landforms as points, point pattern analysis lends itself as method of choice to learn something about the mechanisms that produce the landforms (Bishop, 2007a).

Early studies using point pattern analysis in geomorphology pertain to the analysis of drumlins (Smalley \& Unwin, 1968; Trenhaile, 1971). For example, Trenhaile (1971) took summits of drumlins mapped in several drumlin fields of southern Ontario to test 
whether their distribution is random, clustered or regular. Comparing drumlin counts in different quadrat sizes with a Poisson model for random patterns and a Dacey model for more regular patterns suggested that drumlin distribution is more regular than random. Trenhaile (1975) assigned the regularity to critical stress levels in the ice and the distribution of boulder-content of the drumlin material. Similar analyses have been conducted to understand the formation of simple and compound barchan dunes on Mars (Bishop, 2007b). Based on ordered neighbour analysis, the study found that dunes exhibit a pattern of uniformity across various spatial scales which Bishop (2007b) interpreted as advanced stage of dune formation towards a steady-state equilibrium.

Point pattern analysis has also been used to analyze sinkholes (Vincent, 1987; Rowlingson \& Diggle, 1993; Galve et al., 2011), cliff erosion (Rohmer \& Dewez, 2015), and landslides (Lombardo et al., 2018, 2019) and thus has direct application in hazard and risk assessment of geomorphic processes. For example, Galve et al. (2011) analysed sinkholes in the Ebro valley where $>50$ sinkholes $\mathrm{km}^{-2} \mathrm{yr}^{-1}$ in an evaporite karst were related to irrigation practices. The performance of the model increased by accounting for clustering which the authors interpreted to reflect a self-reinforcing process between sinkholes and the subsurface in the near vicinity. Landslide susceptibility analysis aims to quantify the spatial probability of landslide occurrence on the basis of local terrain conditions. Statistical techniques include weights-of-evidence (Bonham-Carter \& Agterberg, 1989; Meyer et al., 2014), logistic regression (Heckmann et al., 2014) or other classification techniques of machine-learning (Korup \& Stolle, 2014). These approaches are usually based on raster data (e.g., elevation) and evaluate the presence or absence of landslides on a per pixel basis, which in fact represents a particular point pattern analysis. For example, the pixel-based logistic regression is approximately equivalent to a homogeneous or inhomogeneous Poisson point process (Baddeley et al., 2010). Studies that use a point process based modelling framework are now increasingly used for susceptibility analysis, and suggest that accounting for latent spatial effects in the form of Cox processes can strongly increase overall prediction performance of these models (Lombardo et al., 2018, 2019).

\section{4 | POINT PROCESSES ON NETWORKS}

Commonly, spatial point processes are analysed in two or three spatial dimensions and time. Frequently, however, the events occur on or alongside networks. Car accidents, for example, are events on a road network whereas supermarkets are locations alongside the road network. Whether on or alongside, the coordinates of these points are constrained by a spatial network (network-constrained events or, in short, network events [Okabe \& Sugihara, 2012]). Paths between points follow the network's edges and thus distances rarely follow direct Euclidean distances. Instead, standard practice is to measure distances in networks by the length of the shortest path, least-cost or resistance distances (Rakshit et al., 2017). To this end, many existing methods in point pattern analysis rely on the Euclidean distance which may be inappropriate or fallacious if applied to network events (Okabe \& Sugihara, 2012; Rakshit et al., 2017; Baddeley et al., 2020) (Figure 1). In addition, much of the methodology developed in two or three spatial dimensions cannot be extended to point processes on networks because network structure differs around different neighbourhoods which creates fundamental problems because stationary processes cannot be defined. This problem is evident when networks have cycles but less relevant if the network is an acyclic graph such as a river network (Baddeley et al., 2017, 2020).

Geomorphological research often pertains to the analysis of networks (Heckmann et al., 2015), in particular river networks. Concomitantly, numerous events exist that are bound to lie on or alongside river networks. For example, riffle-pool and step-pool sequences are phenomena that exhibit regular distances (Tarboton et al., 1989; Knighton, 1998; Golly et al., 2019), which should be measured along the river rather than the Euclidean distance. Landslide dams, bank collapses, and beaver dams are other spatially random phenomena which can be observed on or alongside rivers and which are possibly controlled by covariates that vary along the river network. Any point pattern recorded along a river network should be associated with distance metrics that account for mechanisms of dispersal which are often linked to network geometry and topology. It may seem straightforward that distances in river networks ought to be calculated in metric units from the outlet or channelheads, but we may also weight these distances by stream flow (Ver Hoef et al., 2006) or elevation (Foltête et al., 2008), or use metrics such as $\chi$-transformed distance (Harkins et al., 2007; Perron \& Royden, 2013) which are increasingly used in the analysis of river profiles and network topology. The choice of distance metric depends on the application and should be guided by additional information (Rakshit et al., 2017). Hence, not all network-constrained points must be analysed using network-derived distances. In an analysis of the spatial patterns of river junctions, for example, Oeppen and Ongley (1975) relied on the planar Euclidean distance.

\section{5 | SOFTWARE IMPLEMENTATION OF POINT PATTERN ANALYSIS ON STREAM NETWORKS}

Few software exist that support the analysis of points that are constrained to lie on or along linear networks. SANET is a Toolbox for ArcGIS but also interfaces to the $\mathrm{R}$ statistical computing software (Okabe et al., 2006, 2018). Its main strength lies within the explorative analysis of network events based on numerous tools (e.g., hotspot analysis via clustering, $\mathrm{K}$ function, nearest-neighbour distance methods). The R package spatstat (Baddeley et al., 2015) has its main focus on point pattern analysis in $2 \mathrm{D}$ or higher dimensions, but includes numerous tools for the analysis of network events, too. Thereby, spatstat - one of the most comprehensive $R$ packages on the CRAN server - implements state-of-the-art techniques of statistical exploration, parametric model fitting, and simulation that can be applied to linear networks.

Although software for the analysis of point pattern analysis exist, we developed our software PPS on top of TopoToolbox, a MATLAB software for topographic analysis (Schwanghart \& Scherler, 2014). TopoToolbox pursues an object-oriented programming approach that simplifies programming tasks which involve gridded digital elevation models (DEMs) and topographic derivatives (Figure 2). A DEM is stored as an object of the class GRIDobj which includes the matrix of elevation values and information on extent, resolution, and coordinate 
reference system. Flow directions are derived from DEMs and are stored as an instance of the class FLOWobj. Using topological sorting of the flow network (Hergarten \& Neugebauer, 2001; Braun \& Willett, 2013), this computational object enables the derivation of drainage basins or computations such as flow accumulation (Schwanghart \& Scherler, 2014). Moreover, FLOWobj is the basis for the delineation of stream networks which are stored as an object of the class STREAMobj. Any computation with stream networks adopts highly efficient algorithms from graph theory (Heckmann et al., 2015). PPS takes advantage of the algorithms that are readily available in TopoToolbox and extends their capabilities to numerous new applications that enable the analysis of point patterns on stream networks (Figure 2).

\section{6 | NUMERIC IMPLEMENTATION AND METHODS OF PPS}

Computational representations of networks can rely on either vector or raster representations (Okabe \& Sugihara, 2012). Being built on the STREAMobj class, PPS uses a hybrid approach. An object of class STREAMobj is derived from a DEM. Thus, the nodes of the PPS stream network refer to cell centres of the DEM. The topology of the network is determined by edges that link the cell centres in cardinal and diagonal directions (8-connectivity). Each node in the network can have attribute values which we refer to as a node-attribute list. An instance of PPS is created by combining a stream network with a point dataset represented by a set of coordinates. If the points are not located on the stream network, they are snapped to the nearest nodes of the stream network either measured by the Euclidean distance or along flow directions on hillslopes, and their distance to the stream can be an attributed of the points. Formally, PPS thus adopts a finepixel approximation of a point pattern (Baddeley et al., 2015).

A PPS object is created using an instance of STREAMobj and a set of coordinates of points, line features (e.g., fault traces) that intersect the stream network, or a model that randomly generates points (Figure 2). Supported models are the binomial and the homogeneous Poisson point process that randomly distribute points on the network given a specified total number of points and intensity (average number of points per unit length), respectively. For example, the pattern in Figure $1(b)$ was generated by a Poisson process with an intensity of $5 \times 10^{-4} \mathrm{~m}^{-1}$. Once initiated, an object of PPS can access numerous functions (or methods) which are summarized in Table 1. The functions are broadly categorized into tools for explorative analysis, inference and simulation, and visualization. In addition, there are a number of conversion tools and other utilities such as interpolation tools.

Explorative analysis of point patterns often begins with kernel density estimates to highlight spatially varying densities of points. While kernel density estimates are straightforward in one-dimensional (1D), 2D or higher dimensions, they are not directly applicable to networks. Conventional 2D kernel density estimators applied to points on river networks may easily overestimate densities along adjacent rivers albeit the rivers may be disconnected (Rakshit et al., 2019). Applying 1D kernel density estimators to networks, however, is also fallacious because it fails to conserve mass where networks branch (Okabe \& Sugihara, 2012; McSwiggan et al., 2017). The function
FIGURE 1 Spatial point processes clearly lack a completely random pattern (a) if we ignore that their locations are constrained by a network. If we take this constraint into account (b), it is more difficult to decide if the observed point pattern is completely random or not
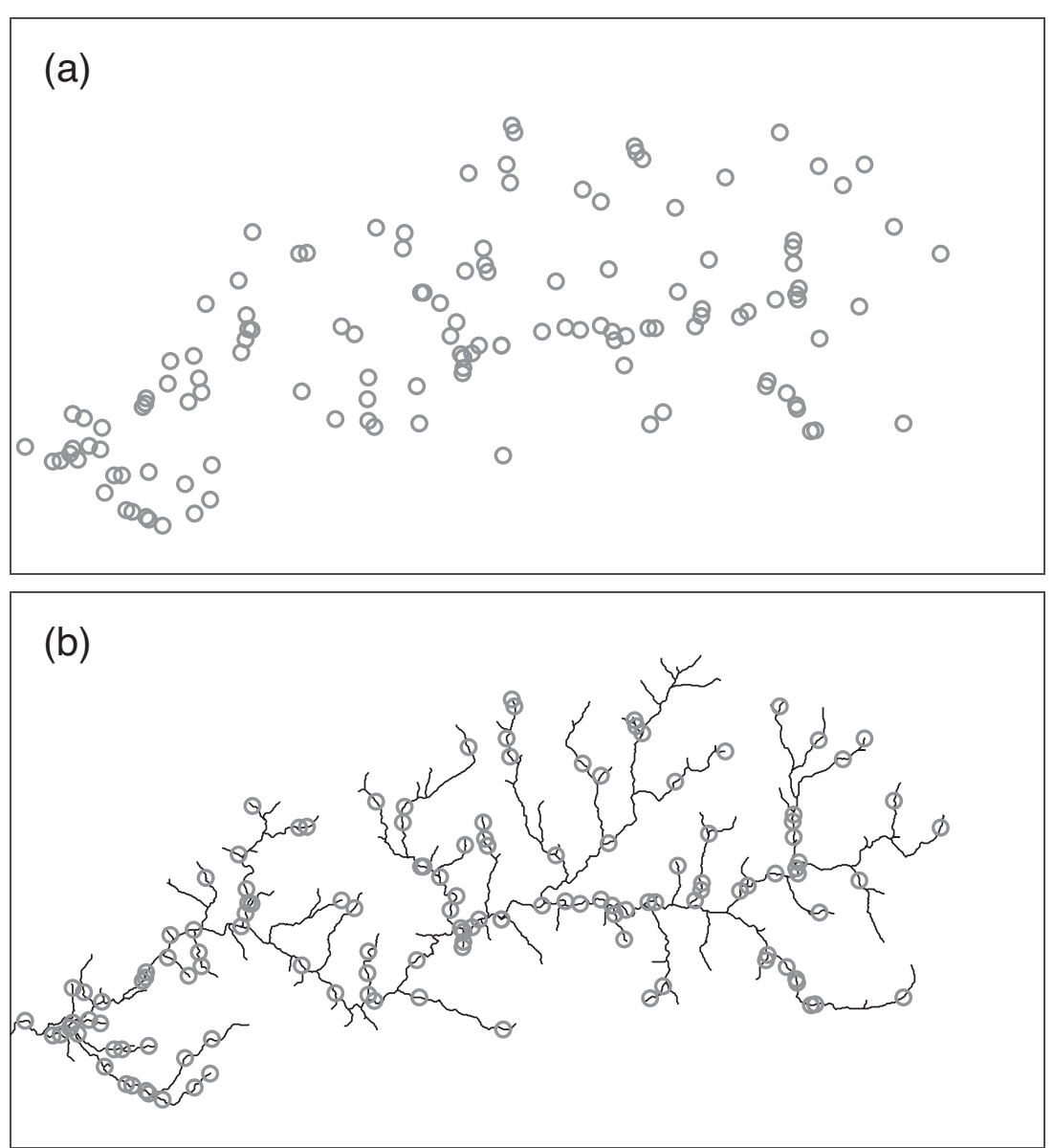


\section{TopoToolbox}

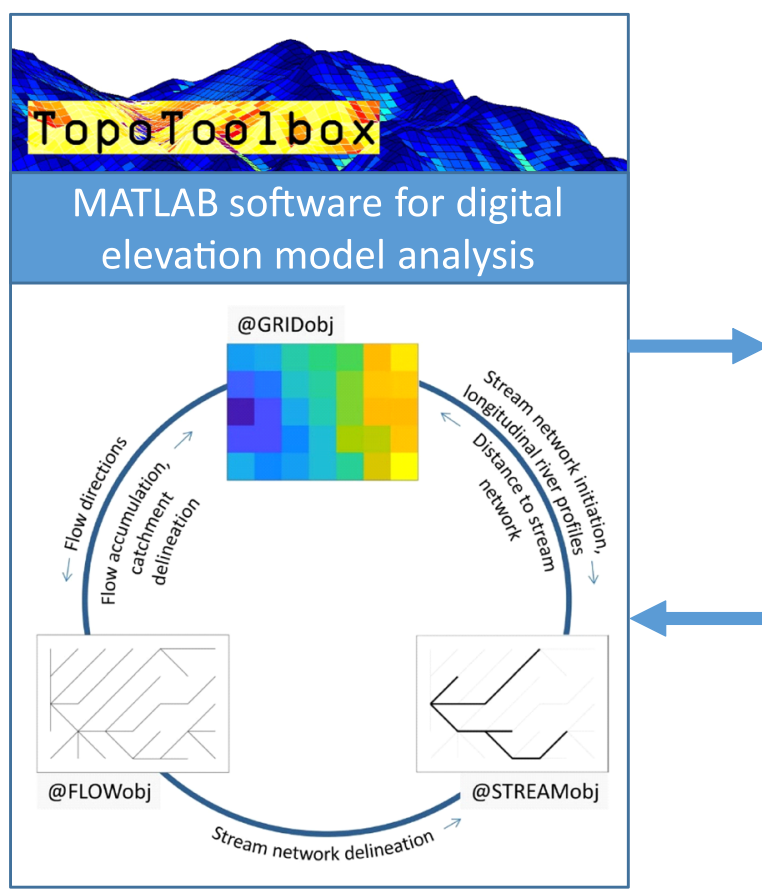

PPS - Point Pattern on

Stream networks

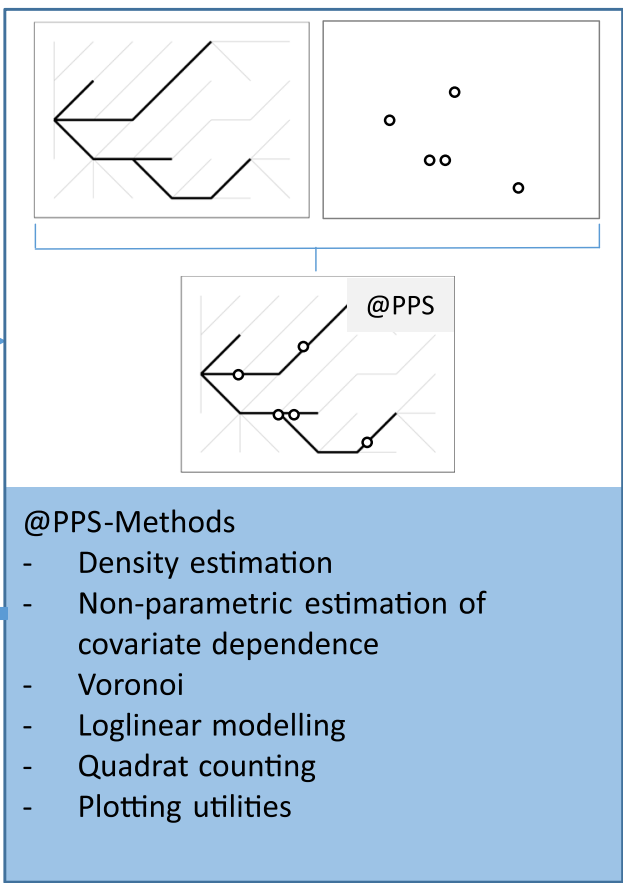

FIG U RE 2 Numerical classes in TopoToolbox and the new PPS class

density adopts the approach of McSwiggan et al. (2017) who implement Gaussian kernel density estimation on networks using an approach that perceives Gaussian kernels as heat kernels and the variable densities along the network as Brownian diffusion (McSwiggan et al., 2017).

Clustering is a technique that groups similar objects to classes. In spatial point pattern analysis this technique is used to detect spatial clusters of points, and to merge them eventually to a set of new points. The function cluster uses hierarchical clustering based on the shortest-path distances of all points (Okabe \& Sugihara, 2012). The resulting spatial clusters can subsequently be merged using the function aggregate, which computes cluster centres by finding the network node that minimizes the sum of squared shortest distances from each point in the cluster.

An important question in the analysis of point patterns is whether the intensity of points depends on spatial covariates. Parametric models describing this dependence have a long tradition in point pattern analysis. These models require that the dependence structure of the model is known. Yet, often we do not know the form of the model, or the form is too complicated to be fitted by a parametric model. Thus, nonparametric estimation provides an important exploratory approach, since it determines the model structure from the data. While nonparametric models do not completely lack parameters, they model the relationship between variables with fewer assumptions, and are thus particularly suitable for explorative analysis (Baddeley et al., 2012). We implemented this nonparametric technique in PPS with the function rhohat which also calculates confidence intervals using bootstrapping.

Nonparametric analysis of covariate dependence makes no assumptions about the shape of the functional relationship between point density and an explanatory variable. However, if the type of relationship is known or hypothesized, then parametric techniques are a more powerful way to analyse the data (Baddeley et al., 2015). The most common model in point pattern analysis is the inhomogeneous Poisson point process model with an intensity which is a loglinear function of the covariates (Baddeley et al., 2015)

$$
\lambda(u)=e^{B(u)+\theta^{\top} \mathbf{Z}(u)}
$$

where $\lambda$ is the intensity of points at locations $u, B$ is a known baseline intensity, and $\theta$ is a vector of $p$ parameters for a vector-valued function $Z(u)=\left[Z_{1}(u) \ldots Z_{p}(u)\right]$. Estimation of the parameters in Equation 1 is detailed in McSwiggan (2019) and based on numerical methods as no explicit closed-form solution is available for the maximum likelihood estimator. Such numerical methods need to rely on discretization using a quadrature scheme. The network representation of PPS derived from DEM pixels provides such a quadrature scheme so that it is straightforward to apply standard techniques such as logistic regression or Poisson regression to estimate the parameters. The function fitloglinear uses fitglm which is part of the MATLAB Statistics and Machine Learning Toolbox and fits generalized linear least squares problems. PPS also features a Bayesian approach to analyse loglinear models. The function bayesloglinear interfaces with the BayesReg Toolbox (Makalic \& Schmidt, 2011, 2016) which provides highly efficient and numerically stable implementations of penalized regression techniques.

PPS features tools to study second-order effects in point processes. For example, the function Kfun calculates the empirical $K$-function on a linear network according to the methods of Okabe and Sugihara (2012) and Ang et al. (2012). The empirical K-function measures the cumulative average number of point pairs ij lying within 
T A B L E 1 Overview on Point Pattern on Stream networks (PPS) functions

\begin{tabular}{|c|c|}
\hline Function & Description \\
\hline \multicolumn{2}{|c|}{ Creating an instance of PPS } \\
\hline PPS & $\begin{array}{l}\text { Constructor function that creates an instance of } \\
\text { class PPS from a stream network } \\
\text { (STREAMobj) and a set of points. } \\
\text { Alternatively, the function can generate } \\
\text { randomly distributed points on stream } \\
\text { networks or calculate intersections with a } \\
\text { network of lines. }\end{array}$ \\
\hline \multicolumn{2}{|l|}{ Explorative analysis } \\
\hline Cluster & Hierarchical spatial clustering of points \\
\hline Density & Kernel density estimator on stream networks \\
\hline Ecdf & Empirical cumulative density function \\
\hline Intensity & Intensity (points per unit distance) \\
\hline Gfun & $\begin{array}{l}\text { G-function (cumulative nearest neighbour } \\
\text { distance statistics) }\end{array}$ \\
\hline Histogram & Histogram of point pattern on stream network \\
\hline Kfun & K-function on a linear network \\
\hline Rhohat & $\begin{array}{l}\text { Nonparametric estimation of covariate } \\
\text { dependence }\end{array}$ \\
\hline \multicolumn{2}{|c|}{ Inference and simulation } \\
\hline Fitloglinear & Fitting a loglinear intensity model \\
\hline Bayesloglinear & Bayesian analysis of a loglinear intensity model \\
\hline Quadratcount & Quadrat counting \\
\hline Random & $\begin{array}{l}\text { Simulation of points using a loglinear intensity } \\
\text { model }\end{array}$ \\
\hline Simulate & Simulation of points using random thinning \\
\hline Ploteffects & $\begin{array}{l}\text { Plot effect of a single predictor variable in a } \\
\text { model }\end{array}$ \\
\hline Roc & Receiver-operating characteristics curve \\
\hline \multicolumn{2}{|l|}{ Other utilities } \\
\hline As & Utility to convert PPS object to other formats \\
\hline Pointdistances & Pairwise distances between points in PPS \\
\hline Voronoi & $\begin{array}{l}\text { Voronoi tessalation of the river network based } \\
\text { on points in PPS }\end{array}$ \\
\hline Hasduplicates & Determine if PPS has duplicate points \\
\hline Removeduplicates & Remove duplicate points in PPS \\
\hline Convhull & Calculate convex hull of points \\
\hline Aggregate & Merge labelled points to a new object of PPS \\
\hline Idw & $\begin{array}{l}\text { Inverse distance weighted interpolation on } \\
\text { stream networks }\end{array}$ \\
\hline Shapewrite & Export PPS as shapefile \\
\hline \multicolumn{2}{|l|}{ Visualization } \\
\hline Plot & Plot stream network with points \\
\hline Plotc & Plot coloured stream network with points \\
\hline Ploteffects & Plot effect of covariate in a loglinear model \\
\hline Plotdz & Plot longitudinal profile with points \\
\hline Plotpoints & Plot points only \\
\hline Wmplot & Plot stream network with points in a webmap \\
\hline
\end{tabular}

a distance $r$ of a typical data point, and standardized by dividing by the intensity $\lambda=n /|L|$ where $n$ is the number of points and $|L|$ is the total length of the network (Baddeley et al., 2015).

$$
\widehat{K}(r)=\frac{|L|}{n(n-1)} \sum_{i=1}^{n} \sum_{\substack{j=1 \\ j \neq i}}^{n} 1\left\{d_{i j} \leq r\right\}
$$

For 2D data, calculation of the $K$-function is straightforward. Yet, if points are constrained to lie on a network, the approach requires that distances are measured as the shortest path distance $d$ along the network (Okabe \& Sugihara, 2012). Compared to Okabe's method, the method by Ang et al. (2012) additionally accounts for network geometry (and thus for edge effects) by weighting point pairs so that the theoretical $K$-function for a homogeneous Poisson process is $K_{\text {pois }}(r)=r$ (Ang et al., 2012). Besides its use as exploratory tool to study secondorder effects in point processes, the $K$-function is used to fit parametric models that include clustering or point interactions (e.g., Cox, Neyman-Scott, Gibbs, or Hawkes models). These models and inferential techniques are currently not supported by PPS.

\section{7 | CASE STUDIES}

Applying the techniques and tools outlined in the previous section, we present three case studies in which the analysis of point patterns is used to extract information about (geomorphological) processes that take place on or alongside rivers. The first case study is based on a simulated river network derived from the numerical landscape evolution model TTLEM (TopoToolbox Landscape Evolution Model) (Campforts et al., 2017). Using simulated homogeneous and inhomogeneous Poisson point processes we showcase several PPS functions. In the second case study, we demonstrate how explorative analysis of knickpoints in river profiles of the Big Tujunga catchment in California can help reveal two phases of landscape rejuvenation. In the third case study, we investigate the spatial distribution of beaver dams in the Tualatin basin, Oregon, and model their geomorphometric constraints. For brevity, some of the data and methods of the case studies are summarized in Table 2 . All data are open and freely available, and scripts and data can be obtained from Schwanghart (2021).

\section{I SYNTHETIC DATA ON A SIMULATED STREAM NETWORK}

The stream network in Figure 3 depicts the fluvial response to block uplift as modelled by the stream power incision model (SPIM). In the following, we simulate two different point patterns and study their properties using the techniques outlined in the previous section. The first realization derives from a homogeneous Poisson point process with a point density of $10^{-5} \mathrm{~m}^{-1}$ (Figure 4a). As expected, quadrat counting and $\chi^{2}$ testing as implemented in the function quadratcount result in a very high $p$-value $(p=0.75)$ that underscores that the observed pattern is very likely under the CSR hypothesis. A nonparametric dependence estimate using elevation as covariate (Figure $4 \mathrm{~b}$ ) suggests that there is no influence of this variable on point density. The steep rise of densities at high elevations is not significant as shown by the bootstrap confidence intervals and likely related to few points at high elevations covered by only a minor portion of the stream network. The empirical network $\mathrm{K}$-function also remains within the acceptance 
TAB LE 2 Data used in the case studies

\begin{tabular}{|c|c|c|c|}
\hline Case study & Simulated & $\begin{array}{l}\text { Knickpoints in the Big Tujunga } \\
\text { catchment }\end{array}$ & Beaver dams in the Tualatin basin \\
\hline Location & $\begin{array}{l}\text { Artificial landscape simulated with } \\
\text { TTLEM (Campforts et al., 2017) }\end{array}$ & California, USA, $34.2^{\circ} \mathrm{N}, 118.2^{\circ} \mathrm{W}$ & Oregon, USA, $45.4^{\circ} \mathrm{N}, 122.8^{\circ} \mathrm{W}$ \\
\hline Catchment area & Several catchments up to $2825 \mathrm{~km}^{2}$ & $293 \mathrm{~km}^{2}$ & $1803 \mathrm{~km}^{2}$ \\
\hline $\begin{array}{l}\text { DEM (spatial } \\
\text { resolution) }\end{array}$ & $100 \mathrm{~m}$ & SRTM-1 (30 m) & $\operatorname{NED}(10 \mathrm{~m})$ \\
\hline Point pattern & Simulated & $\begin{array}{l}52 \text { knickpoints detected by } \\
\text { knickpointfinder }\end{array}$ & 510 beaver dams from Smith (2019) \\
\hline Additional data & - & $\begin{array}{l}\text { Vector data with faults from (USGS and } \\
\text { NMBMMR, 2019) }\end{array}$ & $\begin{array}{l}\text { Stream network vector data from } \\
\text { Nagel et al. (2017) }\end{array}$ \\
\hline
\end{tabular}

aParameter values used: Block uplift with $2 \mathrm{~mm} \mathrm{yr}^{-1}$, simulation time: 400,000 years, stream-power incision model: $K=10^{-4}, m=0.5, n=1$. For a complete list of parameters see Schwanghart (2021).

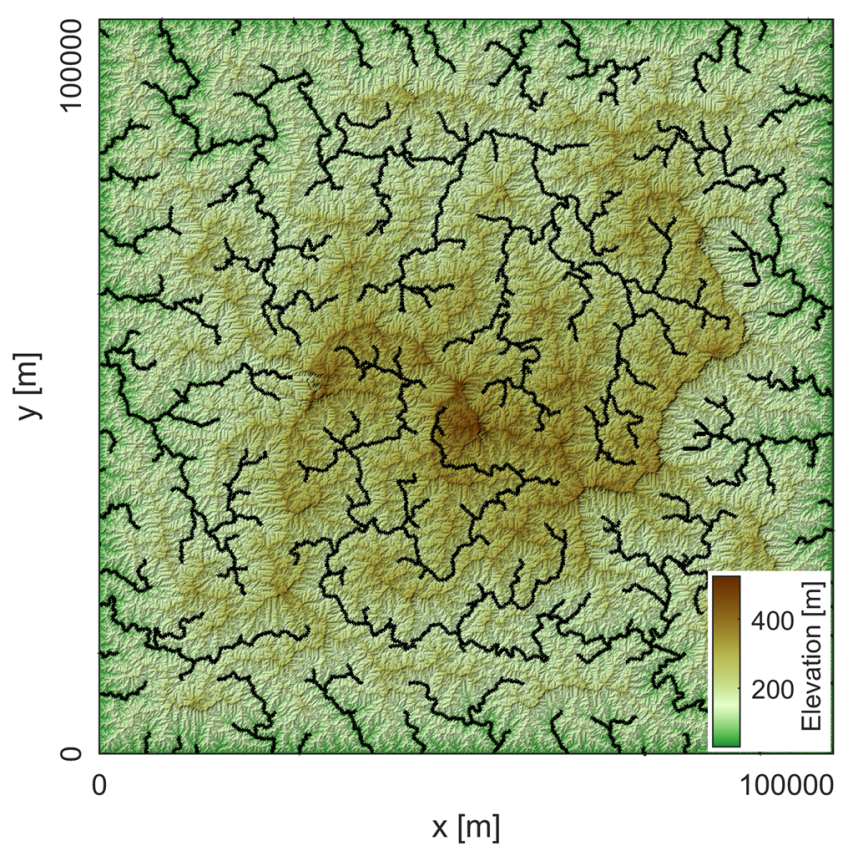

FI G URE 3 Simulated landscape and river network used for generating synthetic point patterns on a network

intervals around the bootstrapped simulation intervals of the theoretical $K$-function (Figure 4c) which suggests that there are no second-order effects. To this end, these results are as expected given that the points were generated by a homogeneous Poisson point process.

In contrast, the second realization shown in Figure 4(d) is simulated based on an inhomogeneous point process, where the intensity $\lambda$ is a function of elevation $z$.

$$
\lambda(z)=e^{-0.0005 z^{2}+0.1 z-14}
$$

The parameters were chosen so that point density reaches a maximum at the average elevation of the stream network whereas only a few points are found at low and high elevations. Such a pattern may reflect a scenario in which an aquatic plant or fish species inhibits only parts of the river network in response to a climatic gradient (da Costa et al., 2018). Quadrat counting and $\chi^{2}$ testing returns a $p$-value of $4.8 \times 10^{-4}$ which strongly supports the notion that the points were not generated under the CSR hypothesis, and nonparametric estimation of dependence reveals the quadratic relation of point density to elevation (Figure 4e).

At this stage, we know that the point pattern was derived from a first-order effect of elevation. Yet, in reality we are rarely able to unambiguously distinguish this effect from one that arises from a second-order effect which produces clustering. In fact, analysing the point pattern with the $\mathrm{K}$-function suggests that the points significantly deviate from the independence assumption of the Poisson process (Figure 4f). A solution to this problem is to model the point pattern using an inhomogeneous point process first, and then to test whether points simulated from this model would exhibit similar $K$-functions as the original data. Here we adopt this pragmatic approach and generate envelopes of the $K$-function based on simulations from the inhomogeneous Poisson model.

The results of this approach are shown in Figure 5. Plotting the effect of elevation in the model fitted to the point pattern reveals the hump-shaped intensity function of points along elevations of the river network (Figure 5a). Using this fitted model when generating simulation envelopes of the $\mathrm{K}$-function shows that the point pattern is consistent with the inhomogeneous Poisson point process with no support of additional clustering that may derive from dependence between the points (Figure $5 b$ ).

\section{9 | KNICKPOINTS IN THE BIG TUJUNGA BASIN}

Rivers in the Big Tujunga catchment in the San Gabriel Mountains feature numerous knickpoints along their longitudinal profiles. These knickpoints are unrelated to lithological boundaries and they are found in relatively narrow elevation bands (Wobus et al., 2006), which suggests that they formed at the range front due to acceleration in slip rate of the Sierra Madre Fault Zone, and the concomitant adjustment of the stream network to the higher uplift rate (DiBiase et al., 2015). The aim of this example is to illustrate how an explorative analysis of knickpoint patterns helps in assessing a model of landscape response times to changes in tectonic uplift.

The most widely used model of fluvial incision and knickpoint migration is the SPIM (Lague, 2014), which states that the rate at which elevations $z$ along a river change over time $t$ is a function of uplift $U$, erosional efficiency $K$, upslope area $A$ and local river gradient 

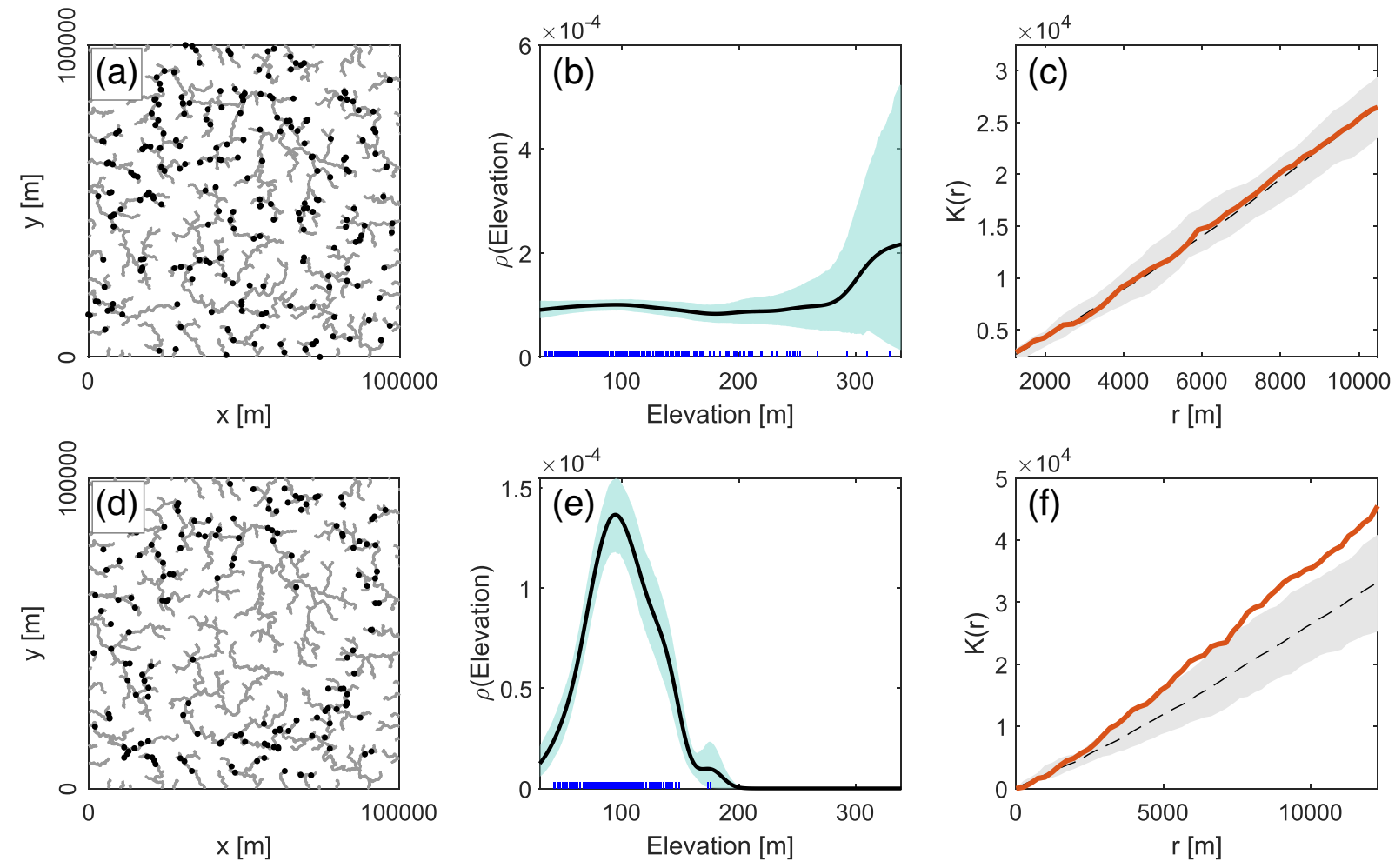

F I G U RE 4 Synthetic random point patterns simulated on river network in Figure 3. (a) Homogeneous Poisson point pattern.

(b) Nonparametric dependence estimation of the pattern in (a) on the covariate elevation. Blue lines indicate covariate values of points, the black line shows the density estimate, and the green shaded area denotes the bootstrapped $95 \%$ confidence intervals of the density estimate. (c) Red line denotes the empirical $\mathrm{K}$ function of the points in (a) and dashed line and grey envelope are simulation mean and envelope based on 19 simulations of a homogeneous Poisson point process. (d) Inhomogeneous point pattern with a pronounced peak in densities at the average elevation of the river network. (e) Same as (b) but derived from the inhomogeneous Poisson point pattern in (d). (f) Same as (c), but derived from the point pattern in (d)
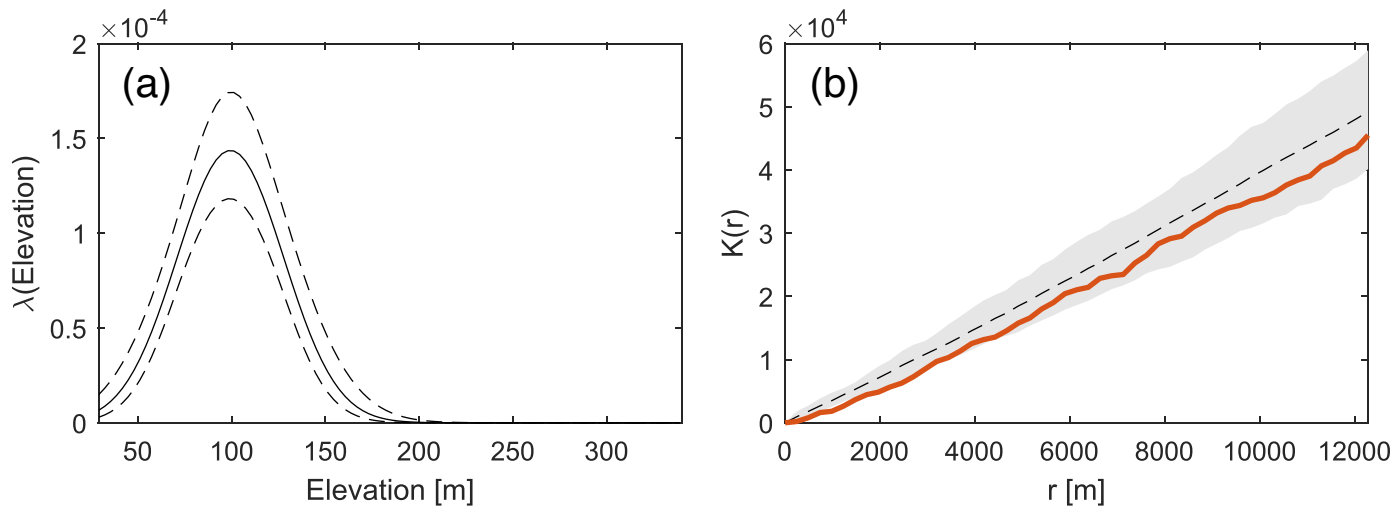

FI G URE 5 (a) Loglinear quadratic model of point density on the network shown in Figure 4(d). (b) Empirical K-function of points on the network and envelope of $\mathrm{K}$-functions calculated from the inhomogeneous Poisson process model in (a)

$$
\frac{\partial z(x)}{\partial t}=U(x, t)-K(x, t) A(x, t)^{m}\left|\frac{d z}{d x}\right|^{n}
$$

where $x$ is the distance from the river outlet along the flow network, and the exponents $m$ and $n$ are empirical constants. Assuming that $U$ and $K$ do not vary in time and space, and that drainage configurations remain unchanged, the steady state channel slope is calculated with

$$
\left|\frac{d z}{d x}\right|=\left(\frac{U}{K}\right)^{\frac{1}{n}} A(x)^{-\frac{m}{n}}
$$

a relation between channel slope and area that predicts an upward concave river profile (Hack, 1957). Based on Equation 4, Harkins et al. (2007) and Perron and Royden (2013) introduced a coordinate transformation which linearizes the power-law relation. The linearization takes the integral of the left and right term in Equation 5 so that elevation becomes a linear function

$$
z(x)=z\left(x_{\mathrm{b}}\right)+\left(\frac{U}{K A_{0}^{m}}\right)^{\frac{1}{n}} \chi
$$




$$
\chi=\int_{x_{\mathrm{b}}}^{x}\left(\frac{A_{0}}{A(x)}\right)^{\frac{m}{n}} d x
$$

with $A_{0}$ (which we set to $10^{6} \mathrm{~m}^{2}$ ) being a reference area and $x_{\mathrm{b}}$ being the location of the base level (Perron \& Royden, 2013). The linear form of the SPIM (with $n=1$ ) predicts that perturbations to river elevations, for example by base level change, migrate upstream as a function of upstream area (Berlin \& Anderson, 2007). The $\chi$-transformation normalizes for upstream area so that any base level change at $x_{b}$ in the past, should result in knickpoints that cluster at a specific value of $\chi$, irrespective of whether the perturbation has travelled upstream the trunk river, or any of its tributaries (Perron \& Royden, 2013; Schwanghart \& Scherler, 2020). Thus, $\chi$ serves as a metric for distances travelled by perturbations upstream in the river network (Fox et al., 2014).

In order to test the knickpoint celerity model (Equation 4) in the Big Tujunga catchment, we derived a stream network with a minimum supporting upslope area of $0.9 \mathrm{~km}^{2}$. Locations of knickpoints were identified with the function knickpointfinder, an automated method of knickpoint identification based on iterative fitting of strictly concave stream profiles that is implemented in TopoToolbox and described in Stolle et al. (2019). Applying a tolerance of $20 \mathrm{~m}$ - which is about the maximum elevation error recorded along streams of the SRTM-1
(Schwanghart \& Scherler, 2017) - yields 52 knickpoints (Figure 6a). Knickpoint height - the elevation difference between the fitted profile and a knickpoint, and a measure taken here for the prominence of each knickpoint - ranges between 22 and $216 \mathrm{~m}$.

The majority of knickpoints are located in the lower part of the catchment (Figure 6a), which is also reflected by the nonparametric estimate (function rhohat) which shows how knickpoint locations depend on the distance to the range-bounding fault (Figure $6 \mathrm{~b}$, dashed grey line). Weighting knickpoints by their squared heights (black line) the occurrence of few but prominent knickpoints in the upper part of the basin is accentuated. We calculated $\chi$ with an $\mathrm{m} / \mathrm{n}$ ratio of 0.4 which has previously been used by Perron and Royden (2013) for the same catchment. Figure 6(c) is similar to Figure 6(b), but depicts density estimates as a function of $\chi$. Again, a non-weighted density estimation highlights the knickpoints in the vicinity to the catchment outlet, whereas weighting them reveals two pronounced peaks at $\chi$ values around 2000 and $5000 \mathrm{~m}$. However, uncertainty intervals (based on bootstrapping) of the density estimates of the second peak are high and reflect the scarcity of knickpoints in the upper part of the catchment.

Mapping the patterns of knickpoint density obtained from the weighted nonparametric dependence model in Figure 6(c) back to spatial coordinates (Figure 7) reveals the expected spatial locations of
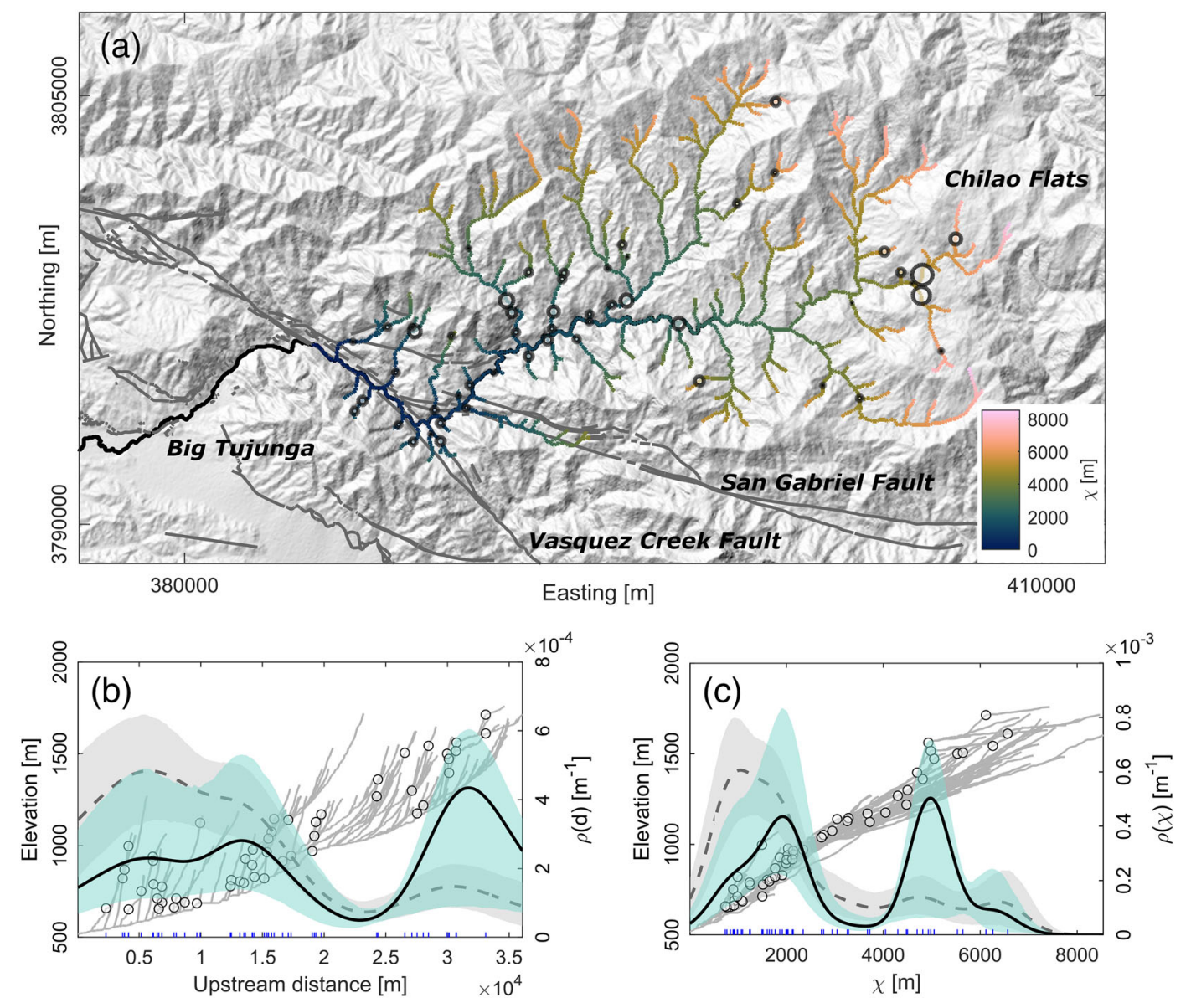

F I G U RE 6 Knickpoint patterns in the Big Tujunga catchment. (a) Hillshade map of the catchment and faults (grey lines), knickpoints and $\chi$-values of the river network. The size of the knickpoint symbols linearly scales with knickpoint heights, which range between 22 and $216 \mathrm{~m}$. (b) Distribution of knickpoints along river profiles (blue lines). Grey dashed line shows the nonparametric dependence of knickpoint locations (with grey envelopes indicating bootstrapped $95 \%$ confidence intervals) as a function of distance from the range-bounding fault. The black line shows the dependence estimate weighted by the knickpoint height. The bandwidth for both estimates is $3000 \mathrm{~m}$. (c) Same as (b), but with the covariate being $\chi$ and bandwidth being $400 \mathrm{~m}$ 
knickpoints. Clearly, as the model was obtained from actual knickpoint locations, both must be consistent to a certain degree. Notwithstanding, actual and expected knickpoint patterns show notable differences in many locations that require explanation. These differences are particularly obvious for the older wave of knickpoints that mark the transition to the Chilao Flats and that are expected to be present high up in other tributaries to the Big Tujunga as well. However, most headwater channels are devoid of knickpoints. There are several explanations for a lack of consistency between expected and actual knickpoint patterns. First, variations in bedrock erodibility manifest themselves in a series of waterfalls in the oversteppened knickzone straddling the Chilao Flats. These waterfalls have been previously found to have slowed down knickpoint retreat by at least an order of magnitude (DiBiase et al., 2015). Other tributaries may lack such resistant layers and thus knickpoints may have already reached channel heads and disappeared. Second, headwater channels may be dominated by debris-flow processes (Stock \& Dietrich, 2003; Hergarten et al., 2016) which may result in faster incision and possibly smearing of knickpoints in the channels. Third, inconsistencies between expected and observed knickpoint patterns may arise from drainage reorganization. Our analysis weighted the most prominent knickpoints, yet these knickpoints may be those that have been particularly affected by divide migration. The margins of the Chilao Flats show highly asymmetric divides (Scherler \& Schwanghart, 2020) (Figure 7) which suggest possibly past and ongoing drainage reorganization. Such reorganization may significantly alter drainage areas and discharge, and thus affect knickpoint celerities which in return could result in more scattered knickpoint locations (Schwanghart \& Scherler, 2020).

\section{0 | BEAVER DAMS IN THE TUALATIN BASIN, OREGON}

Beavers are ecosystem engineers that build dams across and alongside rivers (Brazier et al., 2020; Larsen et al., 2020). These wood accumulations increase the storage of water, sediment, organic matter and nutrients on floodplains, and thus have several ecological benefits (Wohl, 2013; Bouwes et al., 2016; Macfarlane et al., 2017). As beaver dams impound water upstream, they also raise the possibility of beaver dam outburst floods. Although such outburst floods are rare, there were cases where such events greatly exceeded discharges of meteorological floods (O'Connor et al., 2013). Given both ecological benefits and outburst hazard, potential beaver dam locations should thus be known for managing river restoration and flood risk.

In this case study, our analysis focuses on topographic controls on the occurrence of beaver dams that can be derived solely from catchment-scale digital elevation data. Several properties determine the degree to which beavers colonize and sustain a population (Gurnell, 1998), and we hypothesize that beaver habitats are primarily a function of stream flow and stream gradient. Beavers require sufficient stream flow as a reliable water source. Yet, rivers should neither be too wide nor too deep to inhibit building and persistence of dams (Gurnell, 1998; Collen \& Gibson, 2000; Macfarlane et al., 2017). At the same time, river gradient should be relatively low to impound sufficiently large areas. Therefore, steep and rocky rivers are generally less favoured by beavers as dams in such streams are susceptible to damage during high-magnitude discharges and have low impounding efficiency (Gurnell, 1998).

To test the above hypothesis, we studied the distribution of beaver dams in the Tualatin basin, Oregon (Table 2, Figure 8a). In our analysis, we used upstream area as proxy for stream flow, which we derived from the DEM using flow accumulation. Anthropogenic features such as bridges and culverts accounted for some artefacts when we computed the stream network from the original DEM. Thus, we used hydrographic data from Nagel et al. (2017), preprocessed the DEM using stream burning (Reuter et al., 2009), and then extracted the stream network based on an area threshold of $0.1 \mathrm{~km}^{2}$. Commonly, stream gradients derived from DEMs fluctuate strongly as they are highly sensitive to errors in the elevation data (Wobus et al., 2006). We therefore smoothed the profiles using constrained regularized smoothing (Schwanghart \& Scherler, 2017) with a
FIGURE 7 Actual and expected spatial patterns of knickpoints in the Big Tujunga basin. The two dashed lines are manually drawn to highlight the two generations of upstream migrating knickpoints and their expected locations. The grey lines depict the drainage divide network (Scherler \& Schwanghart, 2020), with blue sections showing asymmetric divides and the inferred movement is indicated by the blue arrows

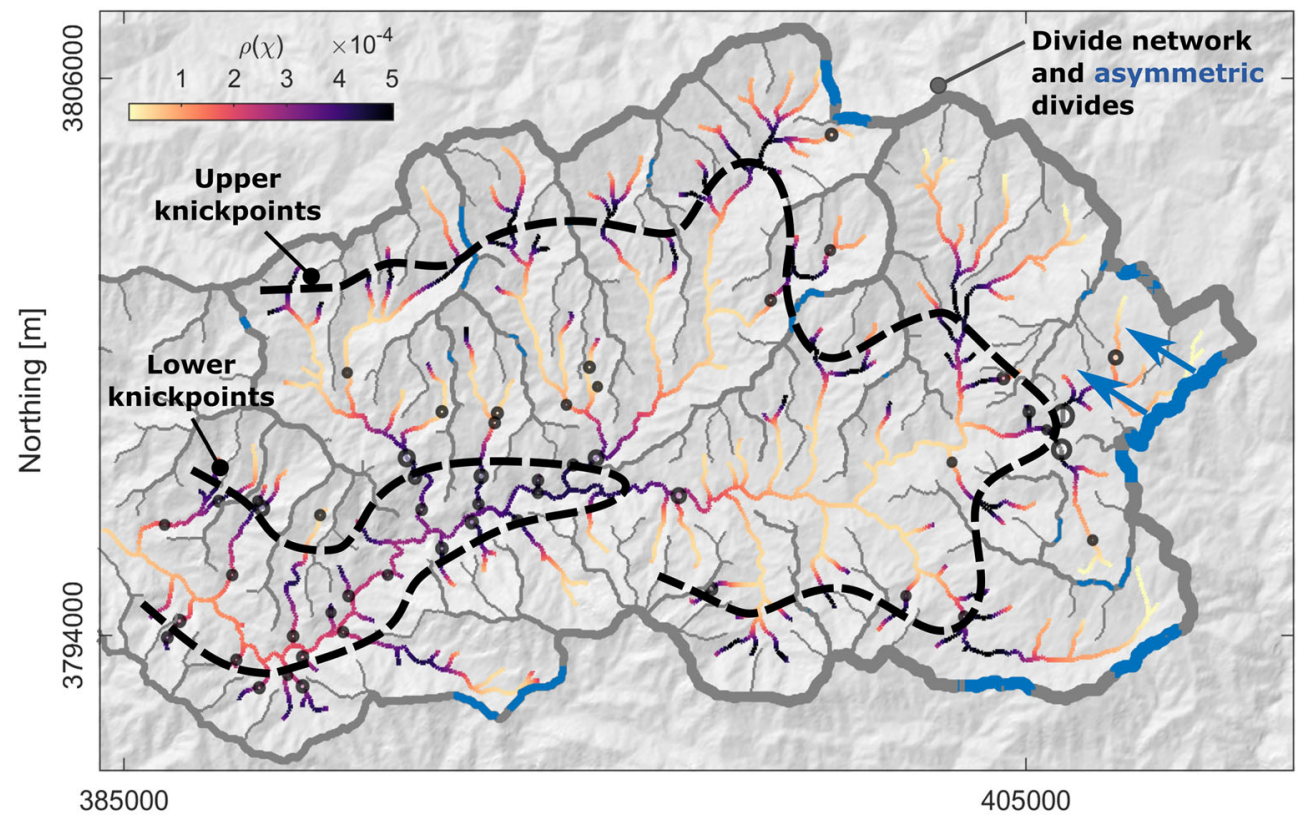

Easting [m] 
smoothing factor of $K=10$. The smoothed elevations are subsequently used to calculate the local stream gradient. Our approach of smoothing the profiles created local gradients that mimic those obtained from a moving window approach with a kernel size of $\sim 200 \mathrm{~m}$.

Beaver dam locations were obtained from the data set (version 2.0) released by Smith (2019). The data was compiled by the US Geological Survey (USGS) and comprises information on 510 beaver dams. Some dam locations are very close to each other and likely correspond to the same beaver populations. Thus, we merged dam locations using the function cluster (Table 1). This function implements hierarchical clustering based on the matrix of shortest-path network distances of all points using an average linkage method. We chose a cutoff of $160 \mathrm{~m}$ and obtained 217 unique locations, which we used for the subsequent analysis.

The pattern of beaver dams (Figure 8a) suggests that their intensity is spatially inhomogeneous. This hypothesis can be tested using techniques such as quadrat counting (function quadratcount). Quadrat counting subdivides the network into roughly equal sized subnetworks and then counts the number of locations within each subnetwork. Under the assumption of CSR, the distribution of points in
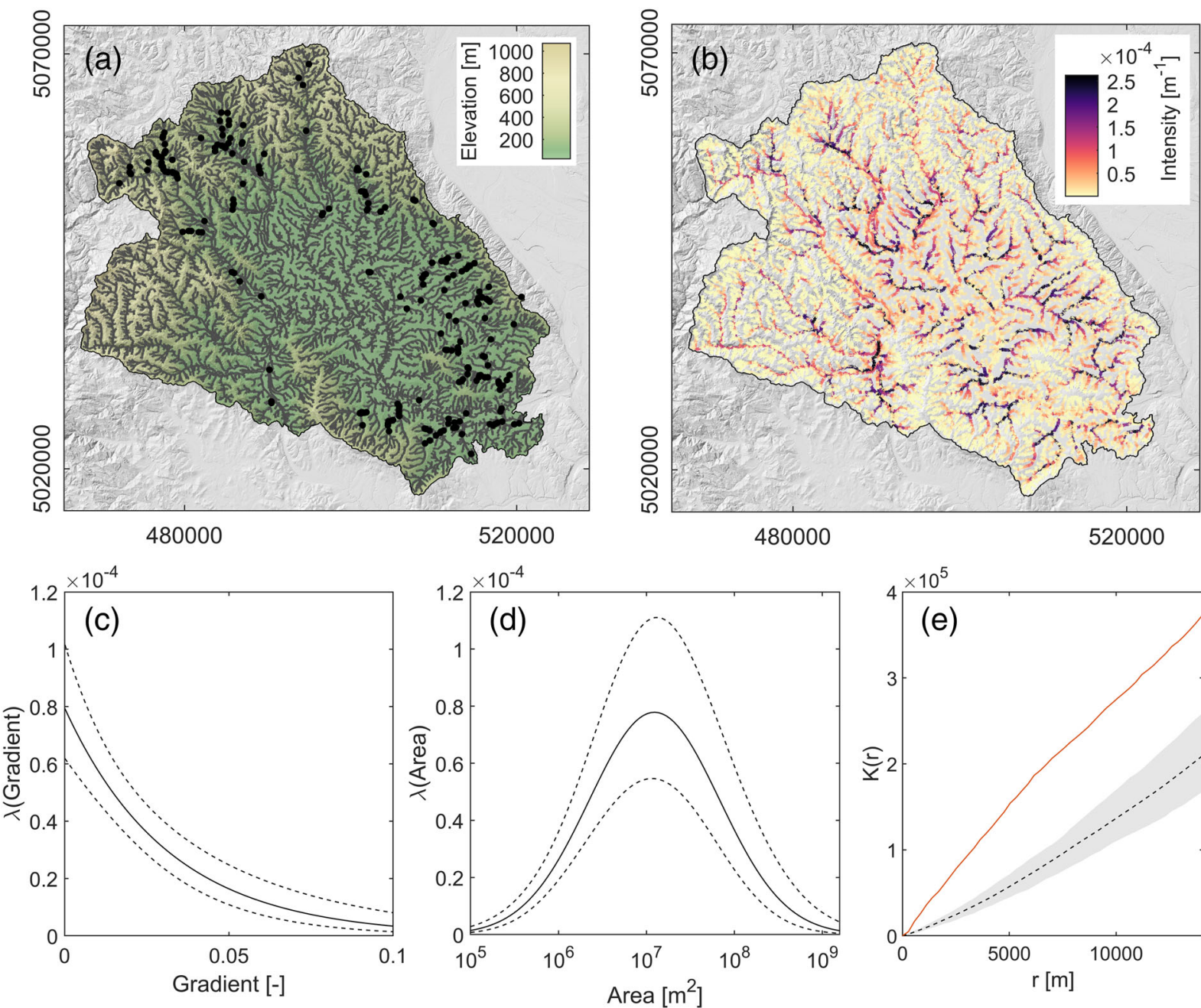

each subnetwork should follow a Poisson distribution with homogeneous intensity, a hypothesis that we investigate with a $\chi^{2}$-test (note that $\chi^{2}$ has nothing in common with the $\chi$-transformation in the previous case study). The $\chi^{2}$-test underscores $(p<0.0001)$ the visual impression that spatial locations of beaver dams in the Tualatin Basin are not completely random.

To test whether drainage area and stream gradient can be used to explain spatial variations in beaver-dam density, we fit a loglinear model with stream gradient and the decadic logarithm of upslope area as independent variables. The loglinear model has an intercept and a first-degree polynomial for gradient and second-degree polynomial for upslope area. Moreover, we add an interaction term (product of both predictors) to investigate whether the interrelationship of stream gradient and upslope area determines spatial beaverdam densities.

We fit the model using stepwise regression which removes parameters or terms that fail to improve the model fit measured by the Akaike-Information Criterion (AIC). From our model, stepwise regression removed the interaction term so that the final model is

$$
\hat{\lambda}(u)=e^{\beta_{0}+\beta_{1} g(u)+\beta_{2} a(u)+\beta_{3} a^{2}(u)}
$$

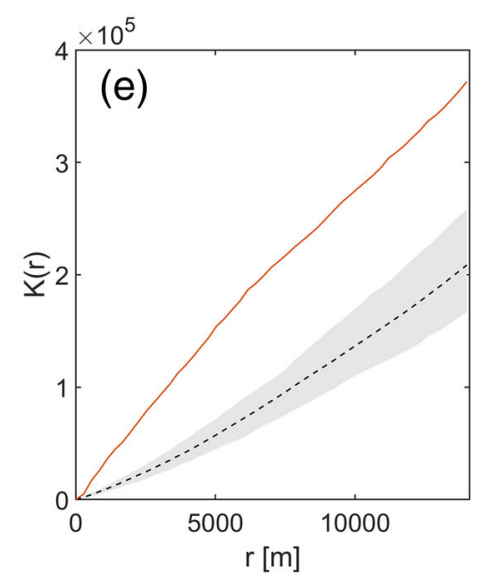

FIG U RE 8 Modelling the locations of beaver dams in the Tualatin basin, Oregon, USA. (a) Hillshade map of the basin, stream network, and the locations of beaver dams (black dots). (b) Modelled intensities of beaver dams using an inhomogeneous Poisson point pattern. (c, d) Fitted responses to a single predictor: (c) stream gradient and (d) drainage area. (e) Empirical $\mathrm{K}$ function for actual beaver dam locations (solid red line) compared to simulation envelopes (shaded area) and average (dashed line) of $\mathrm{K}$ functions obtained from 19 random point patterns derived from the inhomogeneous Poisson model 
where $\hat{\lambda}$ is the estimated density of beaver dams (Figure $8 \mathrm{~b}), \beta_{0}$ is an offset, and $\beta_{1-3}$ are the parameters for stream gradient $g$ and the decadic logarithm of upslope area $a$ and its quadratic form, respectively. Overall, the model is highly significant compared to a model with a pure offset $\left(p=7.28 \times 10^{-82}\right)$ and the area under the ROC (receiver-operating characteristic) curve, a measure of aggregated classification performance, is 0.85 (0.83-0.86 simulation confidence intervals). The values for the parameters, their uncertainties and individual $p$-values are listed in Table 3 and the fitted responses to the single variables are shown in Figure 8(c, d).

Although the model provides a reasonable fit to the data, it may neglect other potential factors. Previous studies found that stream depth, sandbar width, and anabranching (secondary rivers, sloughs) as well as access to forage are important controls on the spatial distribution of beaver dams (e.g. Scrafford et al., 2018). The available data and the representation of the flow network by D8 flow directions do not permit us to represent these factors. In addition, beaver dams entail hydrologic (creating wetlands), hydraulic (slow down runoff), geomorphic (sediment trapping), and ecological feedbacks (subirrigation of downstream valley bottoms that promotes establishment and expansion of riparian vegetation); all of which tend to increase stream complexity and channel-floodplain connectivity (Macfarlane et al., 2017). These feedbacks may lead to spatial clustering, as beaver-engineered river reaches may increase local beaver populations. Our model does not capture such clustering effects. However, to test whether the data exhibits such spatial clustering after accounting for the first-order effects of stream gradient and discharge, we calculated the $\mathrm{K}$-function. The empirical $\mathrm{K}$-function of the actual distribution of beaver dams and those that were simulated by the inhomogeneous Poisson process model (Figure 8e) show that the actual distribution of beaver dams exhibits a much stronger clustering compared to the simulated points. Whether this clustering may evolve from individual beaver populations or positive feedbacks exerted by beavers on their habitats remains shrouded. However, modelling such interactions may improve with more advanced point pattern models, whose treatment is beyond the scope of this study and which are currently not implemented in PPS.

\section{1 | DISCUSSION}

The three case studies showcase the new TopoToolbox object class PPS, which supports the analysis of point patterns on stream networks. The studies have in common that different geomorphic phenomena can be conceptualized as point processes that occur on or alongside stream networks. Knickpoints in bedrock rivers, for example, migrate upstream along the river network, but with no apparent

T A B LE 3 Estimated parameters of a loglinear model of beaverdam locations in the Tualatin basin, Oregon, USA

\begin{tabular}{|lllcl} 
& Estimate & Standard error & $\mathrm{t}$-Statistics & $\mathrm{p}$-Value \\
\hline $\boldsymbol{\beta}_{\mathbf{0}}$ & -51.99 & 4.62 & -11.26 & $2.18 \mathrm{E}-29$ \\
$\boldsymbol{\beta}_{1}$ & -31.60 & 4.99 & -6.33 & $2.48 \mathrm{E}-10$ \\
$\boldsymbol{\beta}_{2}$ & 12.97 & 1.36 & 9.55 & $1.35 \mathrm{E}-21$ \\
$\boldsymbol{\beta}_{3}$ & -0.91 & 0.10 & -9.20 & $3.68 \mathrm{E}-20$ \\
\hline
\end{tabular}

link between adjacent rivers. This strict constraint could be relaxed when analysing beaver populations because beavers may roam freely between adjacent rivers when expanding into new territory. Our analysis did not take the potential movement of beavers between streams into account, which may particularly affect second-order effects of beaver dams. To this end, investigating such effects would require a broader definition of distance metrics on networks (Baddeley et al., 2017, 2020; Rakshit et al., 2017) and on stream networks in particular that combine distances along and aside stream networks.

Our case study on the spatial distribution of knickpoints relied on weighting knickpoints by their height. Yet, we did not include such attributes in the analysis of beaver dams, although these biogeomorphic features commonly have highly variable sizes (Turowski et al., 2013), which could be used to weight observations in the models. Yet, such attribute data was not available in this study. In general, there are techniques that extend point pattern analysis to the analysis of marked point patterns, a suite of methods to explore and model point patterns with attribute data. Yet, these techniques are currently not implemented in PPS.

PPS relies on the geographic representation of geomorphic objects or features as points, and streams as lines or network of lines. It follows that the studied phenomena must be conceptualized as points, although they may often have volumes associated with them and they may have vaguely defined limits or be overlapping (Goodchild, 2011; Smith, 2011; Evans, 2012). As common in geographic information system (GIS) analysis, such a representation embodies spatial scale to some degree. For point pattern analysis, it is crucial to remember that spacing between points may be observed if points actually represent areal non-overlapping features. Moreover, the fine-pixel approximation used in PPS means that points are constrained to lie on nodes of the stream network, which are derived from the underlying DEM. The representation of network events is thus tightly linked to the spatial resolution of the DEM. This also entails that the density of points should not be too high, as it may cause points to share the same locations, a situation usually not foreseen in point pattern analysis. Assuming CSR (the homogeneous Poisson process model), the choice of an appropriate spatial resolution for a given intensity may rely on the constraint that the probability for having two or more coincident points should be low. Finding this probability relies on the solution to the birthday paradox which provides the probability that in $n$ randomly chosen network nodes there are two or more duplicate nodes. Figure 9 shows the probabilities that a network with a total length of $2500 \mathrm{~km}$ (which is approximately the length of the streams in the network shown in Figure 3) contains duplicate points for a given intensity and spatial resolution. If we accept a probability of $10 \%$ for two or more points sharing the same node, point intensities of up to $2.9 \times 10^{-4}, 9.2 \times 10^{-5}$ and $2.9 \times 10^{-5} \mathrm{~m}^{-1}$ can be modelled at spatial resolutions of 1,10 , and $100 \mathrm{~m}$, respectively, using PPS. High point intensities require high spatial resolutions to be adequately represented by the fine pixel approximation used by PPS. Note, however, that even if coincident points exist, these do not invalidate methods to unravel first-order effects from point processes.

An additional note of caution concerns the transferability of models. The distance between two vertices is a lower bound of the true distance, if we assume that all line vertices are located on the central line of the river (Goodchild, 2011). In TopoToolbox and 


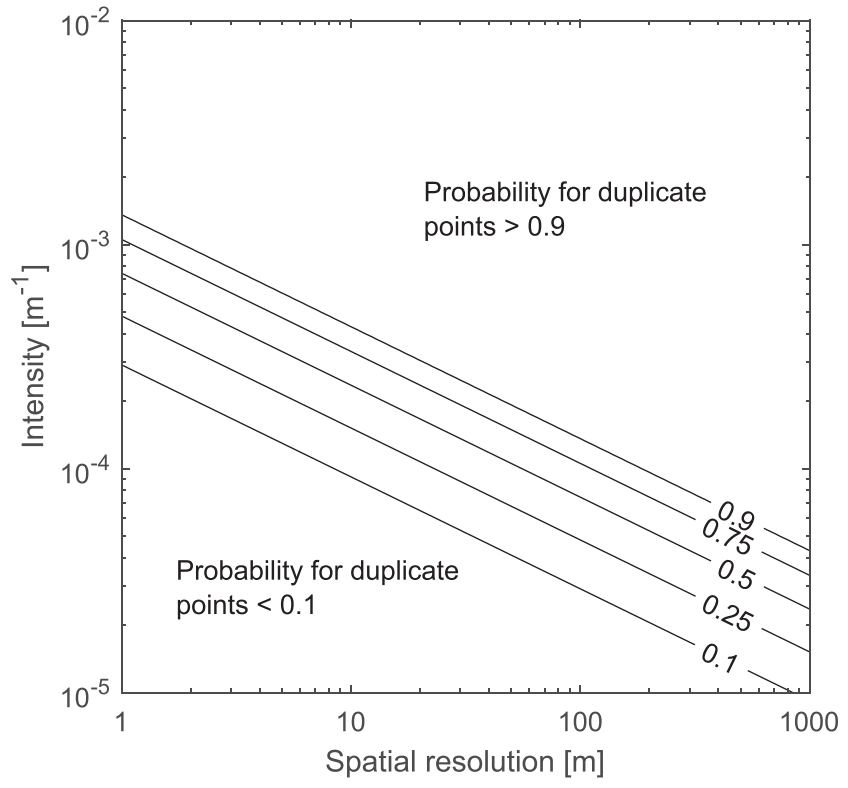

FIG URE 9 Probabilities for duplicate points in pixels of a stream network as represented by PPS. Probabilities are computed for a network with $2500 \mathrm{~km}$ length which is about the length of the network shown in Figure 3. Probabilities are calculated using an approximation to the birthday paradox according to which the probability $p$ of having two or more points in one pixel is $p(n, d) \approx 1-$ $e^{-\frac{n^{2}}{2 d}}$ where $n$ is the number of points and $d$ is the number of pixels in the network

thus also PPS, the geometry of stream networks is determined by the Moore neighbourhood (8-connectivity) of the D8 flow direction algorithm. This means that cell centres are rarely on the centreline of the actual stream and that river lengths can be both overestimated and underestimated. Underestimation typically occurs for low resolution grids, while overestimation occurs for high-resolution DEMs and relatively straight rivers. Relative errors in river length have been estimated to range from 5 to $7 \%$ for distances calculated on raster data structures, and up to $>30 \%$ for very coarse resolution DEMs (da Paz et al., 2008). In point pattern analysis, these errors will affect estimates of point intensity and interpoint distances. Hence, models developed with a particular DEM, cannot be easily transferred to other DEMs without analysing how these DEMs affect distance calculations. To this end, this is a problem that pixel-based logistic regression models commonly face (Baddeley et al., 2010).

Only a few functions in PPS account for the directedness of stream networks. For example, the function pointdistances enables to calculate nearest neighbour distances in upstream and downstream directions. Most functions, however, treat the network as undirected and thus neglect that many processes on stream networks have a natural direction. Sediment and nutrient transport, for example, will follow the downstream flow of water, while mobile knickpoints commonly migrate upstream. Although techniques of geostatistical interpolation exist that account for the directional dependence of dispersal in river networks (Garreta et al., 2010), in point pattern analysis, these approaches are rare and a relatively new field of research (Rasmussen \& Christensen, 2019).

We envision numerous other potential applications of PPS. Beyond the case studies shown, potential applications include the analysis of sediment tracers, the locations of outsized boulders, wood jams, or landslide dams. In addition, PPS may be applied in ecology for modelling of aquatic species based on sightings, for example. Finally, once point pattern models have been trained, they can be adopted in simulation tools such as the TTLEM (Campforts et al., 2017) to study the stochastic forcing of landslides on riverscapes in long-term landscape development.

\section{2 | CONCLUSIONS}

PPS is a new numeric class in TopoToolbox for the analysis of point patterns on stream networks. In two case studies, we analysed geomorphic phenomena whose locations are constrained to river networks. Combining explorative analysis of the locations of knickpoints with $\chi$-analysis in the Big Tujunga catchment, PPS allowed us to identify two distinct generations of knickpoints. In our analysis of beaver dams, we have shown that the inhomogeneous Poisson process models implemented in PPS helps to infer different geomorphological factors on beaver habitats.

PPS focuses on exploratory data analysis and fitting of inhomogeneous Poisson point processes, which both allow studying covariates that control the spatial density of points. In addition, PPS features numerous tools for simulation and visualization. Incorporation into TopoToolbox enables ease of access to these new functionalities from within one computational environment. Besides the presented case studies, we anticipate other applications of PPS for studying processes in fluvial geomorphology and landscape evolution, but also the distribution of aquatic and riparian species or other phenomena that are constrained to occur on or alongside rivers.

\section{ACKNOWLEDGEMENTS}

The authors thank Cassandra D. Smith and the USGS for access to the data on beaver dam locations. Opentopography was used to download some of the DEMs used in this study. Some figures were made using Scientific Colormaps (Crameri, 2018). This research has been partially funded by Deutsche Forschungsgemeinschaft (DFG, German Science Foundation) - SFB 1294/1-318763901. The authors thank an anonymous reviewer and Stuart Grieve for comments on a previous version of the manuscript.

\section{CONFLICT OF INTEREST}

The authors declare no competing interests.

\section{DATA AVAILABILITY STATEMENT}

PPS is part of TopoToolbox and can be downloaded from https:// github.com/wschwanghart/topotoolbox. The data used here are from public domain resources. MATLAB scripts for the case studies including data can be downloaded from Schwanghart (2021).

\section{ORCID}

Wolfgang Schwanghart (D) https://orcid.org/0000-0001-6907-6474 Dirk Scherler (D) https://orcid.org/0000-0003-3911-2803

\section{REFERENCES}

Ang, Q.W., Baddeley, A. \& Nair, G. (2012) Geometrically corrected second order analysis of events on a linear network, with applications to 
ecology and criminology. Scandinavian Journal of Statistics, 39(4), 591-617. https://doi.org/10.1111/j.1467-9469.2011.00752.x

Baddeley, A., Berman, M., Fisher, N.I., Hardegen, A., Milne, R.K., Schuhmacher, D., et al. (2010) Spatial logistic regression and changeof-support in Poisson point processes. Electronic Journal of Statistics, 4(none), 1151-1201. https://doi.org/10.1214/10-EJS581

Baddeley, A., Chang, Y.-M., Song, Y. \& Turner, R. (2012) Nonparametric estimation of the dependence of a spatial point process on spatial covariates. Statistics and its Interface, 5(2), 221-236. https://doi.org/ 10.4310/SII.2012.v5.n2.a7

Baddeley, A., Nair, G., Rakshit, S. \& McSwiggan, G. (2017) "Stationary" point processes are uncommon on linear networks. Stat, 6(1), 68-78. https://doi.org/10.1002/sta4.135

Baddeley, A., Nair, G., Rakshit, S., McSwiggan, G. \& Davies, T.M. (2020) Analysing point patterns on networks - a review. Spatial Statistics, 42, 100435. https://doi.org/10.1016/j.spasta.2020.100435

Baddeley, A., Rubak, E. \& Turner, R. (2015) Spatial Point Patterns: Methodology and Applications with R. Boca Raton, FL: Apple Academic Press Inc.

Berlin, M.M. \& Anderson, R.S. (2007) Modeling of knickpoint retreat on the Roan Plateau, western Colorado. Journal of Geophysical Research: Earth Surface, 112(F3), 1-16. https://doi.org/10.1029/ 2006JF000553

Bishop, M.A. (2007a) Point pattern analysis of eruption points for the Mount Gambier volcanic sub-province: a quantitative geographical approach to the understanding of volcano distribution. Area, 39(2), 230-241. https://doi.org/10.1111/j.1475-4762.2007.00729.x

Bishop, M.A. (2007b) Point pattern analysis of north polar crescentic dunes, Mars: A geography of dune self-organization. Icarus, 191(1), 151-157. https://doi.org/10.1016/j.icarus.2007.04.027

Bonham-Carter, G.F. \& Agterberg, F.P. (1989) Integration of geological datasets for gold exploration in Nova Scotia. In Digital Geologic and Geographic Information Systems. Van Driel, J. N. \& Davis, J. C., Canada: Geological Survey of Canada, Washington, D. C: American Geophysical Union, 15-23. https://doi.wiley.com/10.1029/ SC010p0015

Bouwes, N., Weber, N., Jordan, C.E., Saunders, W.C., Tattam, I.A., Volk, C., et al. (2016) Ecosystem experiment reveals benefits of natural and simulated beaver dams to a threatened population of steelhead (Oncorhynchus mykiss). Scientific Reports, 6(1), 1-12. https://doi.org/ 10.1038/srep28581

Brandolini, F. \& Carrer, F. (2020) Terra, Silva et Paludes. Assessing the role of alluvial geomorphology for Late-Holocene settlement strategies (Po Plain - N Italy) through point pattern analysis. Environmental Archaeology, 0, 1-15. https://doi.org/10.1080/14614103.2020. 1740866

Braun, J. \& Willett, S.D. (2013) A very efficient O(n), implicit and parallel method to solve the stream power equation governing fluvial incision and landscape evolution. Geomorphology, 180-181, 170-179. https://doi.org/10.1016/j.geomorph.2012.10.008

Brazier, R.E., Puttock, A., Graham, H.A., Auster, R.E., Davies, K.H. \& Brown, C.M.L. (2020) Beaver: Nature's ecosystem engineers. WIREs Water, 8, e1494. https://doi.org/10.1002/wat2.1494

Campforts, B., Schwanghart, W. \& Govers, G. (2017) Accurate simulation of transient landscape evolution by eliminating numerical diffusion: the TTLEM 1.0 model. Earth Surface Dynamics, 5(1), 47-66. https:// doi.org/10.5194/esurf-5-47-2017

Clark, C.D., Ely, J.C., Spagnolo, M., Hahn, U., Hughes, A.L.C. \& Stokes, C.R. (2018) Spatial organization of drumlins. Earth Surface Processes and Landforms, 43(2), 499-513. https://doi.org/10.1002/esp.4192

Collen, P. \& Gibson, R.J. (2000) The general ecology of beavers (Castor spp.), as related to their influence on stream ecosystems and riparian habitats, and the subsequent effects on fish - a review. Reviews in Fish Biology and Fisheries, 10(4), 439-461. https://doi.org/10.1023/ A:1012262217012

Crameri, F. (2018) Geodynamic diagnostics, scientific visualisation and StagLab 3.0. Geoscientific Model Development, 11(6), 2541-2562. https://doi.org/10.5194/gmd-11-2541-2018

Cressie, N., Frey, J., Harch, B. \& Smith, M. (2006) Spatial prediction on a river network. Journal of Agricultural, Biological, and Environmental
Statistics, 11(2), 108571106X110649

127-150.

https://doi.org/10.1198/

da Costa, I.D., Petry, A.C. \& Mazzoni, R. (2018) Responses of fish assemblages to subtle elevations in headwater streams in southwestern Amazonia. Hydrobiologia, 809(1), 175-184. https://doi.org/10.1007/ s10750-017-3463-1

da Paz, A.R., Collischonn, W., Risso, A. \& Mendes, C.A.B. (2008) Errors in river lengths derived from raster digital elevation models. Computers \& Geosciences, 34(11), 1584-1596. https://doi.org/10.1016/j. cageo.2007.10.009

DiBiase, R.A., Whipple, K.X., Lamb, M.P. \& Heimsath, A.M. (2015) The role of waterfalls and knickzones in controlling the style and pace of landscape adjustment in the western San Gabriel Mountains, California. Geological Society of America Bulletin, 127(3-4), 539-559. https://doi. org/10.1130/B31113.1

Diggle, P.J., Moraga, P., Rowlingson, B. \& Taylor, B.M. (2013) Spatial and spatio-temporal log-Gaussian Cox processes: Extending the geostatistical paradigm. Statistical Science, 28(4), 542-563. https:// doi.org/10.1214/13-STS441

Evans, I.S. (2012) Geomorphometry and landform mapping: What is a landform? Geomorphology, 137(1), 94-106. https://doi.org/10.1016/j. geomorph.2010.09.029

Fan, X., Dufresne, A., Siva Subramanian, S., Strom, A., Hermanns, R., Tacconi Stefanelli, C., et al. (2020) The formation and impact of landslide dams - state of the art. Earth-Science Reviews, 203, 103116. https://doi.org/10.1016/j.earscirev.2020.103116

Foltête, J.C., Berthier, K. \& Cosson, J.F. (2008) Cost distance defined by a topological function of landscape. Ecological Modelling, 210(1-2), 104-114. https://doi.org/10.1016/j.ecolmodel.2007. 07.014

Fonstad, M.A. \& Marcus, W.A. (2003) Self-organized criticality in riverbank systems. Annals of the Association of American Geographers, 93(2), 281-296. https://doi.org/10.1111/1467-8306.9302002

Fox, M., Goren, L., May, D.A. \& Willett, S.D. (2014) Inversion of fluvial channels for paleorock uplift rates in Taiwan. Journal of Geophysical Research: Earth Surface, 119(9), 1853-1875. https://doi.org/10. 1002/2014JF003196

Gailleton, B., Mudd, S.M., Clubb, F.J., Peifer, D. \& Hurst, M.D. (2019) A segmentation approach for the reproducible extraction and quantification of knickpoints from river long profiles. Earth Surface Dynamics, 7, 211-230. https://doi.org/10.5194/esurf-7-211-2019

Galve, J.P., Remondo, J. \& Gutiérrez, F. (2011) Improving sinkhole hazard models incorporating magnitude-frequency relationships and nearest neighbor analysis. Geomorphology, 134(1-2), 157-170. https://doi.org/10.1016/j.geomorph.2011.05.020

Ganio, L.M., Torgersen, C.E. \& Gresswell, R.E. (2005) A geostatistical approach for describing spatial pattern in stream networks. Frontiers in Ecology and the Environment, 3(3), 138-144. https://doi.org/10. 1890/1540-9295(2005)003[0138:AGAFDS]2.0.CO;2

Garreta, V., Monestiez, P. \& Ver Hoef, J.M. (2010) Spatial modelling and prediction on river networks: up model, down model or hybrid? Environmetrics, 21, 439-456. https://doi.org/10.1002/env.995

Gatrell, A.C., Bailey, T.C., Diggle, P.J. \& Rowlingson, B.S. (1996) Spatial point pattern analysis and its application in geographical epidemiology. Transactions of the Institute of British Geographers, 21(1), 256. https://doi.org/10.2307/622936

Golly, A., Turowski, J.M., Badoux, A. \& Hovius, N. (2019) Testing models of step formation against observations of channel steps in a steep mountain stream. Earth Surface Processes and Landforms, 44(7), 1390-1406. https://doi.org/10.1002/esp.4582

Goodchild, M.F. (2011) Scale in GIS: An overview. Geomorphology, 130 (1-2), 5-9. https://doi.org/10.1016/j.geomorph.2010.10.004

Gurnell, A.M. (1998) The hydrogeomorphological effects of beaver dam-building activity. Progress in Physical Geography: Earth and Environment, 22(2), 167-189. https://doi.org/10.1177/ 030913339802200202

Hack, J.T. (1957) Studies of longitudinal stream profiles in Virginia and Maryland. USGS Professional Paper, 295, 45-97.

Harkins, N., Kirby, E., Heimsath, A., Robinson, R. \& Reiser, U. (2007) Transient fluvial incision in the headwater of the Yellow River, 
northeastern Tibet, China. Journal of Geophysical Research, 112, F03S04. https://doi.org/10.1029/2006JF000570

Hawkes, A.G. (1971) Point spectra of some mutually exciting point processes. Journal of the Royal Statistical Society: Series B: Methodological, 33, 438-443. https://doi.org/10.1111/j.2517-6161.1971.tb01530.x

Heckmann, T., Gegg, K., Gegg, A. \& Becht, M. (2014) Sample size matters: Investigating the effect of sample size on a logistic regression susceptibility model for debris flows. Natural Hazards and Earth System Sciences, 14, 259-278. https://doi.org/10.5194/nhess-14-259-2014

Heckmann, T., Schwanghart, W. \& Phillips, J.D. (2015) Graph theoryrecent developments of its application in geomorphology. Geomorphology, 243, 130-146. https://doi.org/10.1016/j.geomorph.2014. 12.024

Hergarten, S. \& Neugebauer, H.J. (2001) Self-organized critical drainage networks. Physical Review Letters, 86(12), 2689-2692. https://doi. org/10.1103/PhysRevLett.86.2689

Hergarten, S., Robl, J. \& Stüwe, K. (2016) Tectonic geomorphology at small catchment sizes - extensions of the stream-power approach and the $\chi$ method. Earth Surface Dynamics, 4(1), 1-9. https://doi.org/10. 5194/esurf-4-1-2016

Kandakji, T., Gill, T.E. \& Lee, J.A. (2020) Identifying and characterizing dust point sources in the southwestern United States using remote sensing and GIS. Geomorphology, 353, 107019. https://doi.org/10.1016/ j.geomorph.2019.107019

Knighton, D. (1998) Fluvial Forms and Processes: A New Perspective, 2 Rev edition. London: Taylor \& Francis.

Korup, O. (2006) Rock-slope failure and the river long profile. Geology, 34 (1), 45-48. https://doi.org/10.1130/G21959.1

Korup, O. (2020) Bayesian geomorphology. Earth Surface Processes and Landforms, 46(1), 151-172. https://doi.org/10.1002/esp.4995

Korup, O. \& Stolle, A. (2014) Landslide prediction from machine learning. Geology Today, 30(1), 26-33. https://doi.org/10.1111/gto.12034

Kraft, C.E., Warren, D.R. \& Keeton, W.S. (2011) Identifying the spatial pattern of wood distribution in northeastern North American streams. Geomorphology, 135(1-2), 1-7. https://doi.org/10.1016/j.geomorph. 2011.07.019

Lague, D. (2014) The stream power river incision model: Evidence, theory and beyond. Earth Surface Processes and Landforms, 39(1), 38-61. https://doi.org/10.1002/esp.3462

Larsen, A., Lane, S.N. \& Larsen, J.R. (2020) Dam busy: beavers and their influence on the structure and function of river corridor hydrology, geomorphology, biogeochemistry and ecosystems [online] Available from: https://eartharxiv.org/repository/view/1733/ (accessed 28 November 2020)

Liang, C., Jaksa, M.B., Kuo, Y.L. \& Ostendorf, B. (2015) Identifying areas susceptible to high risk of riverbank collapse along the Lower River Murray. Computers and Geotechnics, 69, 236-246. https://doi.org/ 10.1016/j.compgeo.2015.05.019

Lombardo, L., Bakka, H., Tanyas, H., van Westen, C., Mai, P.M. \& Huser, R. (2019) Geostatistical modeling to capture seismic-shaking patterns from earthquake-induced landslides. Journal of Geophysical Research: Earth Surface, 124(7), 1958-1980. https://doi.org/10.1029/ 2019JF005056

Lombardo, L., Opitz, T. \& Huser, R. (2018) Point process-based modeling of multiple debris flow landslides using INLA: An application to the 2009 Messina disaster. Stochastic Environmental Research and Risk Assessment, 32(7), 2179-2198. https://doi.org/10.1007/s00477018-1518-0

Macfarlane, W.W., Wheaton, J.M., Bouwes, N., Jensen, M.L., Gilbert, J.T., Hough-Snee, N. \& Shivik, J.A. (2017) Modeling the capacity of riverscapes to support beaver dams. Geomorphology, 277, 72-99. https:// doi.org/10.1016/j.geomorph.2015.11.019

Makalic, E. \& Schmidt, D.F. (2011) A Simple Bayesian Algorithm for Feature Ranking in High Dimensional Regression Problems. Berlin, Heidelberg: Springer. 223-230 pp.

Makalic, E. \& Schmidt, D.F. (2016) High-Dimensional Bayesian Regularised Regression with the BayesReg Package [online] Available from: https://arxiv.org/abs/1611.06649v3 (accessed 30 January 2020)

McSwiggan, G. (2019) Spatial point process methods for linear networks with applications to road accident analysis, The University of Western
Australia [online] Available from: https://api.research-repository.uwa.edu. au/portalfiles/portal/81039500/THESIS_DOCTOR_OF_PHILOSOPHY MCSWIGGAN_Gregory_Edward_2020.pdf (accessed 19 January 2021)

McSwiggan, G., Baddeley, A. \& Nair, G. (2017) Kernel density estimation on a linear network. Scandinavian Journal of Statistics, 44(2), 324-345. https://doi.org/10.1111/sjos.12255

Meyer, N.K., Schwanghart, W., Korup, O., Romstad, B. \& Etzelmüller, B. (2014) Estimating the topographic predictability of debris flows. Geomorphology, 207, 114-125. https://doi.org/10.1016/j.geomorph. 2013.10.030

Molkenthin, C., Donner, C., Reich, S., Zöller, G., Hainzl, S., Holschneider, M., et al. (2020) GP-ETAS: Semiparametric Bayesian inference for the spatio-temporal Epidemic Type Aftershock Sequence model. arXiv:2005.12857 [physics, stat] [online] Available from: http://arxiv.org/abs/2005.12857 (accessed 18 January 2021)

Moradi, M.M., Rodríguez-Cortés, F.J. \& Mateu, J. (2018) On kernel-based intensity estimation of spatial point patterns on linear networks. Journal of Computational and Graphical Statistics, 27(2), 302-311. https://doi.org/10.1080/10618600.2017.1360782

Nagel, D., Wollrab, S., Parkes-Payne, E., Peterson, E., Isaak, D. \& Ver Hoef, J. (2017) National Stream Internet hydrography datasets for spatial-stream-network (SSN) analysis [online] Available from: https:// www.fs.fed.us/rm/boise/AWAE/projects/NationalStreamInternet/ NSI_network.htm

O'Connor, J.E., Clague, J.J., Walder, J.S., Manville, V. \& Beebee, R.A. (2013) Outburst Floods. In Treatise on Geomorphology. Amsterdam Elsevier; 475-510.[online] Available from: https://linkinghub. elsevier.com/retrieve/pii/B9780123747396002517 (accessed 30 September 2019)

Oeppen, B.J. \& Ongley, E.D. (1975) Spatial point processes applied to the distribution of river junctions. Geographical Analysis, 7(2), 153-171. https://doi.org/10.1111/j.1538-4632.1975.tb01032.x

Ogata, Y. (1998) Space-time point-process models for earthquake occurrences. Annals of the Institute of Statistical Mathematics, 50(2), 379-402. https://doi.org/10.1023/A:1003403601725

Okabe, A., Okunuki, K. \& Shiode, S. (2006) SANET: A toolbox for spatial analysis on a network. Geographical Analysis, 38(1), 57-66. https:// doi.org/10.1111/j.0016-7363.2005.00674.x

Okabe, A., Okunuki, K.-I. \& SANET Team. (2018) SANET. A spatial analysis along networks (version 4.1). Tokyo, Japan

Okabe, A., Satoh, T. \& Sugihara, K. (2009) A kernel density estimation method for networks, its computational method and a GIS-based tool. International Journal of Geographical Information Science, 23(1) 7-32. https://doi.org/10.1080/13658810802475491

Okabe, A. \& Sugihara, K. (2012) Spatial analysis along networks: Statistical and computational methods. Chicheser: John Wiley \& Sons 10 1002/9781119967101.

Perron, J.T. \& Royden, L. (2013) An integral approach to bedrock river profile analysis. Earth Surface Processes and Landforms, 38(6), 570-576. https://doi.org/10.1002/esp.3302

Phillips, J.D. \& Lutz, J.D. (2008) Profile convexities in bedrock and alluvial streams. Geomorphology, 102(3-4), 554-566. https://doi.org/10. 1016/j.geomorph.2008.05.042

Rakshit, S., Baddeley, A. \& Nair, G. (2019) Efficient code for second order analysis of events on a linear network. Journal of Statistical Software, 90, 1-37. https://doi.org/10.18637/jss.v090.i01

Rakshit, S., Davies, T., Moradi, M.M., McSwiggan, G., Nair, G., Mateu, J. \& Baddeley, A. (2019) Fast kernel smoothing of point patterns on a large network using two-dimensional convolution. International Statistical Review, 87, 531-556. https://doi.org/10. 1111/insr.12327

Rakshit, S., Nair, G. \& Baddeley, A. (2017) Second-order analysis of point patterns on a network using any distance metric. Spatial Statistics, 22, 129-154. https://doi.org/10.1016/j.spasta.2017.10.002

Rasmussen, J.G. \& Christensen, H.S. (2019) Point processes on directed linear network. arXiv:1812.09071 [math, stat] [online] Available from: http://arxiv.org/abs/1812.09071 (accessed 11 March 2020)

Reuter, H.I., Hengl, T., Gessler, P. \& Soille, P. (2009) Preparation of DEMs for geomorphometric analysis. In: Hengl, T. \& Reuter, H.I. (Eds.) 
Geomorphometry. Concepts, Software, Applications. Amsterdam: Elsevier, pp. 87-120.

Rohmer, J. \& Dewez, T. (2015) Analysing the spatial patterns of erosion scars using point process theory at the coastal chalk cliff of MesnilVal, Normandy, northern France. Natural Hazards and Earth System Sciences, 15(2), 349-362. https://doi.org/10.5194/nhess-15-3492015

Rowlingson, B.S. \& Diggle, P.J. (1993) Splancs: Spatial point pattern analysis code in S-plus. Computers \& Geosciences, 19(5), 627-655. https:// doi.org/10.1016/0098-3004(93)90099-Q

Scherler, D. \& Schwanghart, W. (2020) Drainage divide networks - part 1: Identification and ordering in digital elevation models. Earth Surface Dynamics, 8(2), 245-259. https://doi.org/10.5194/esurf-8-2452020

Schwanghart, W. (2021) Examples of PPS (Point pattern on stream networks) for TopoToolbox. Zenodo. https://doi.org/10.5281/zenodo. 4658411

Schwanghart, W. \& Kuhn, N.J. (2010) TopoToolbox: A set of Matlab functions for topographic analysis. Environmental Modelling \& Software, 25(6), 770-781. https://doi.org/10.1016/j.envsoft.2009.12.002

Schwanghart, W. \& Scherler, D. (2014) TopoToolbox 2 - MATLAB-based software for topographic analysis and modeling in Earth surface sciences. Earth Surface Dynamics, 2(1), 1-7. https://doi.org/10.5194/ esurf-2-1-2014

Schwanghart, W. \& Scherler, D. (2017) Bumps in river profiles: Uncertainty assessment and smoothing using quantile regression techniques. Earth Surface Dynamics, 5(4), 821-839. https://doi.org/10.5194/ esurf-5-821-2017

Schwanghart, W. \& Scherler, D. (2020) Divide mobility controls knickpoint migration on the Roan Plateau (Colorado, USA). Geology, 48(7), 698-702. https://doi.org/10.1130/G47054.1

Scott, D.N., Wohl, E. \& Yochum, S.E. (2019) Wood Jam Dynamics Database and Assessment Model (WooDDAM): A framework to measure and understand wood jam characteristics and dynamics. River Research and Applications, 35(9), 1466-1477. https://doi.org/10. 1002/rra.3481

Scrafford, M.A., Tyers, D.B., Patten, D.T. \& Sowell, B.F. (2018) Beaver habitat selection for $24 \mathrm{yr}$ since reintroduction north of Yellowstone National Park. Rangeland Ecology \& Management, 71(2), 266-273. https://doi.org/10.1016/j.rama.2017.12.001

Skoien, J.O., Merz, R. \& Blöschl, G. (2006) Top-kriging -- geostatistics on stream networks. Hydrology and Earth System Sciences, 10(2), 277-287. https://doi.org/10.5194/hess-10-277-2006

Smalley, I.J. \& Unwin, D.J. (1968) The formation and shape of drumlins and their distribution and orientation in drumlin fields. Journal of Glaciology, 7(51), 377-390. https://doi.org/10.3189/S0022143000020591

Smith, C.D. (2019) Beaver dam locations and beaver activity in the Tualatin Basin, Oregon, between 2011 and 2019 (version 2.0, November 2019). US Geological Survey data release. Reston, VA: US Geological Survey. DOI: https://doi.org/10.5066/F7PZ57QP

Smith, M.J. (2011) Digital mapping: Visualisation, interpretation and quantification of landforms. In: Smith, M.J., Paron, P. \& Griffiths, J.S. (Eds.) Developments in Earth Surface Processes. London: Elsevier, pp. 225-251.
Sochan, A., Łagodowski, Z.A., Nieznaj, E., Beczek, M., Ryzak, M., Mazur, R., et al. (2019) Splash of solid particles as a stochastic point process. Journal of Geophysical Research: Earth Surface, 124(11), 2475-2490. https://doi.org/10.1029/2018JF004993

Stock, J. \& Dietrich, W.E. (2003) Valley incision by debris flows: Evidence of a topographic signature. Water Resources Research, 39(4), ESG1.1-24. https://doi.org/10.1029/2001WR001057

Stolle, A., Schwanghart, W., Andermann, C., Bernhardt, A., Fort, M., Jansen, J.D., et al. (2019) Protracted river response to medieval earthquakes. Earth Surface Processes and Landforms, 44(1), 331-341. https://doi.org/10.1002/esp.4517

Tacconi Stefanelli, C., Catani, F. \& Casagli, N. (2015) Geomorphological investigations on landslide dams. Geoenvironmental Disasters, 2(21), 1-15. https://doi.org/10.1186/s40677-015-0030-9

Tarboton, D.G., Bras, R.L. \& Rodriguez-Iturbe, I. (1989) Scaling and elevation in river networks. Water Resources Research, 25(9), 2037-2051. https://doi.org/10.1029/WR025i009p02037

Trenhaile, A.S. (1971) Drumlins: Their distribution, orientation, and morphology. The Canadian Geographer/Le Géographe Canadien, 15(2), 113-126. https://doi.org/10.1111/j.1541-0064.1971.tb00147.x

Trenhaile, A.S.A.S. (1975) The morphology of a drumlin field. Annals of the Association of American Geographers, 65(2), 297-312. https://doi. org/10.1111/j.1467-8306.1975.tb01038.x

Turowski, J.M., Badoux, A., Bunte, K., Rickli, C., Federspiel, N. \& Jochner, M. (2013) The mass distribution of coarse particulate organic matter exported from an Alpine headwater stream. Earth Surface Dynamics, 1, 1-11. https://doi.org/10.5194/esurf-1-1-2013

USGS. \& NMBMMR. (2019) Quaternary fault and fold database for the United States [online] Available from: https://www.usgs.gov/ natural-hazards/earthquake-hazards/faults (accessed 1 August 2019)

Ver Hoef, J.M., Peterson, E. \& Theobald, D. (2006) Spatial statistical models that use flow and stream distance. Environmental and Ecological Statistics, 13(4), 449-464. https://doi.org/10.1007/s10651-0060022-8

Vincent, P.J. (1987) Spatial dispersion of polygonal karst sinks. Zeitschrift für Geomorphologie, 31, 65-72.

Wobus, C., Whipple, K.X., Kirby, E., Snyder, N., Johnson, J., Spyropolou, K., et al. (2006) Tectonics from topography: Procedures, promise, and pitfalls. GSA Special Papers, 398, 55-74. https://doi.org/10.1130/ 2006.2398(04)

Wohl, E. (2013) Floodplains and wood. Earth-Science Reviews, 123, 194-212. https://doi.org/10.1016/j.earscirev.2013.04.009

How to cite this article: Schwanghart W, Molkenthin C Scherler D. A systematic approach and software for the analysis of point patterns on river networks. Earth Surf. Process. Landforms. 2021;1-16. https://doi.org/10.1002/ esp. 5127 